\title{
AN ORGANIZATIONAL CULTURAL ASSESSMENT OF THE SOLAR ENERGY RESEARCH INSTITUTE
}

\author{
by
}

Deborah A. Crouch and Sonja B. Haber

August 1991

DEPARTMENT OF NUCLEAR ENERGY, BROOKHAVEN NATIONAL LABORATORY UPTON, NEW YORK 11973 


\section{NOTICE}

This report was prepared as an account of work sponsored by an agency of the United States Government. Neither the United States Government nor any agency thereof, or any of their employees, makes any warranty, expressed or implied, or assumes any legal liability or responsibility for any third party's use, or the results of such use, of any information, apparatus, product or process disclosed in this report, or represents that its use by such third party would not infringe privately owned rights. of Energy

The views expressed in this report are not necessarily those of the U.S. Department 
BNL-46530

INFORMAL REPORT

\title{
AN ORGANIZATIONAL CULTURAL ASSESSMENT OF THE SOLAR ENERGY RESEARCH INSTITUTE
}

\author{
Prepared by: \\ Deborah A. Crouch and Sonja B. Haber \\ Engineering Technology Division \\ Department of Nuclear Energy \\ Brookhaven National Laboratory/Associated Universities, Inc. \\ Upton, New York 11973
}

August 1991

Prepared for:

U.S. Department of Energy

Washington, D.C. 20585

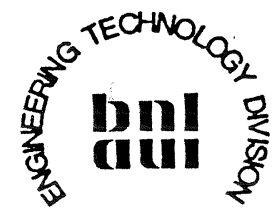

DNE 


\section{EXECUTIVE SUMMARY}

An Organizational Cultural Assessment (OCA) was performed at the Solar Energy Research Institute (SERI) by administering an Organizationai Culture Survey (OCS) that queried employees on the subjects of organizational culture, various aspects of communications, employee commitment, work group cohesion, coordination of work, environmental concerns, hazardous nature of work, safety and overall job satisfaction. The purpose of the OCS is to measure in a quantitative and objective way the notion of "culture;" that is, the values, attitudes, and beliefs of the individuals working within the organization. In addition, through the OCS, a broad sample of individuals can be reached that would probably not be interviewed or observed during the course of a typical assessment. The OCS also provides a descriptive profile of the organization at one point in time that can then be compared to a profile taken at a different point in time to assess changes in the culture of the organization.

The OCS administration at SERI was the seventh to occur at a Department of Energy (DOE) facility in conjunction with a Tiger Team Assessment. The OCS was administered at SERI in large groups. Times were assigned to groups of employees based on the beginning letter of their last names. Of the 578 employees at SERI, 492 completed the survey, yielding a response rate of 85.1 percent. The distribution of response was varied across divisions/offices with the lowest response rate of 62.4 percent in the Mechanical and Industrial Technology Division, and the highest response rate of 102.7 percent in the Administrative Services Division. This greater than 100 percent response rate is due either to a small number of individuals who did not appropriately identify their division when completing the background information sheet, or to an inaccurate reporting of the number of employees within each division/office. All data from the OCS is presented in group summaries, by division, supervisory level, and staff classification. Statistically significant differences between groups are identified and discussed.

The most notable finding which emerges from the OCA conducted at SERI is that it is a very homogeneous organization as indicated by the few statistically significant differences found between divisions/offices, staff classifications, and supervisory levels. The results also indicate SERI to be an organization which places a large amount of emphasis on those behaviors which are considered "constructive" (i.e., Humanistic-Encouraging, Affiliative, Achievement, Self-Actualizing) and, although to a lesser extent, on those behaviors which could be regarded as "passive/defensive" (i.e., Approval, Conventional, Dependent, Avoidance).

While the overall mean score on the Communication - Interaction Scale indicated that most employees of SERI desire interaction with others in the organization, the mean scores on the Communication - Accuracy, Communication - Trust, and Communication - Satisfaction Scales were not correspondingly as high. Thus, SERI employees have lower trust in, perceived accuracy in, and satisfaction with communications, than their desire for interaction with others in the organization. Overall commitment to the organization and cohesion with one's working group were high.

The mean value obtained on the Hazard Scale was low, a finding which was not unexpected given the type of research and work which is conducted at SERI. Similarly, the SERI sample had low mean values on both the Offsite and Onsite Consequences Questions. Despite this, the obtained mean value on the Safety Scale was high, indicating that SERI employees still find those behaviors which re important to safety to be helpful in doing their job well.

No statistically significant differences between divisions/offices at SERI were obtained on the Organizational Culture Inventory (OCI) scales. The differences obtained between divisions/offices on the Hazard scale and the Offsite and Onsite Consequence Questions were consistent with the types of 
work in which the divisions/offices engage. The Administrative Services Division, Director's Office, and Energy and Environmental Analysis Division scored low on these scales and the Environment, Safety and Health Section and the Fuels and Chemicals Research and Engineering Division scored somewhat higher. These differences, as well as others obtained, indicate that the two divisions/offices which were most dissimilar were the Administrative Services Division and the Environment, Safety, and Health Section. These divisions/offices were statistically significantly different on every scale in which a significant difference was obtained.

Statistically significant differences between staff classifications were obtained only on the Conventional (C4) and Hazard Scales. The differences obtained were consistent with the work functions of the classifications. No statistically significant differences were identified between supervisory levels. This is yet another indication of the apparently homogeneous culture which exists at SERI. 


\section{CONTENTS}

EXECUTIVE SUMMARY $\ldots \ldots \ldots \ldots \ldots \ldots \ldots \ldots \ldots \ldots \ldots \ldots \ldots \ldots \ldots \ldots$ iii

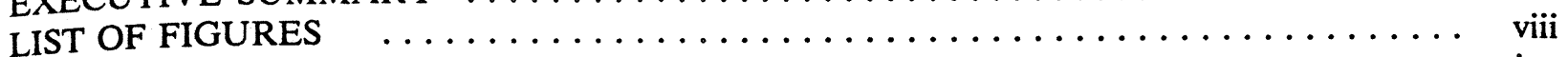

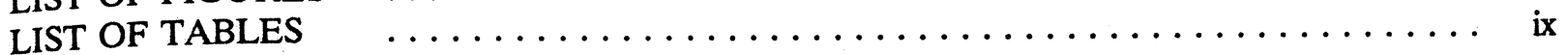

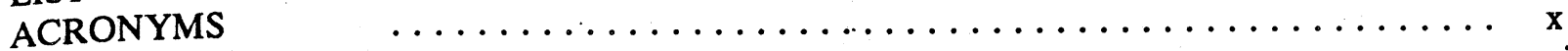

ACKNOWLEDGEMENT $\ldots \ldots \ldots \ldots \ldots \ldots \ldots \ldots \ldots \ldots \ldots \ldots \ldots \ldots \ldots \ldots \ldots \ldots \ldots$

1. INTRODUCTION $\ldots \ldots \ldots \ldots \ldots \ldots \ldots \ldots \ldots \ldots \ldots \ldots \ldots \ldots \ldots \ldots$

2. METHODOLOGY $\ldots \ldots \ldots \ldots \ldots \ldots \ldots \ldots \ldots \ldots \ldots \ldots \ldots \ldots \ldots \ldots$

3. ORGANIZATIONAL DESCRIPTION $\ldots \ldots \ldots \ldots \ldots \ldots \ldots \ldots \ldots \ldots \ldots$

4. ORGANIZATIONAL CULTURE SURVEY SCALES AND RESULTS $\ldots \ldots \ldots$

4.1 Organizational Culture Inventory $\ldots \ldots \ldots \ldots \ldots \ldots \ldots \ldots \ldots \ldots \ldots \ldots \ldots$

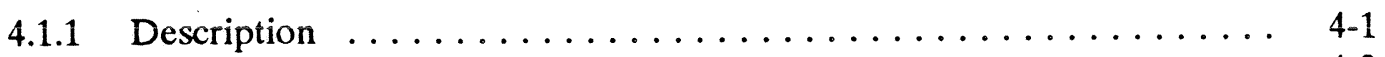

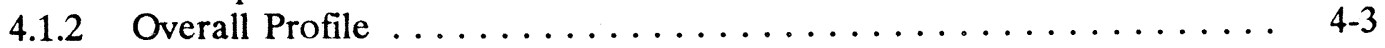

4.1.3 Differences Between Divisions/Offices on the OCI ......... $4-4$

4.1.4 Differences Between Staff Classifications on the OCI . . . . . . . . . 4-4

4.1.5 Differences Between Supervisory Levels on the OCI ......... 4-5

4.2 Communication Scales $\ldots \ldots \ldots \ldots \ldots \ldots \ldots \ldots \ldots \ldots \ldots \ldots$

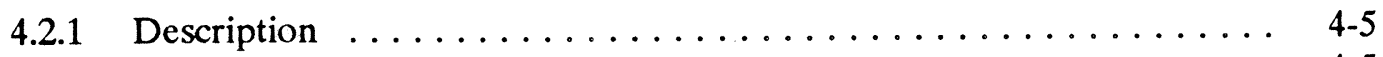

4.2 .2 Overall SERI Results . . . . . . . . . . . . . . . . . 4-5

4.2.3 Differences Between Divisions/Offices on the Communication Scales . 4-6

4.2.4 Differences Between Staff Classifications on the Communication Scales 4-6

4.2.5 Differences Between Supervisory Levels on the Communication Scales 4-6

4.3 Commitment Scale $\ldots \ldots \ldots \ldots \ldots \ldots \ldots \ldots \ldots \ldots \ldots \ldots \ldots$

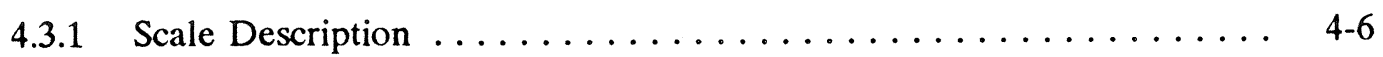

4.3.2 Overall SERI Results ..................... 4-7

4.3.3 Differences Between Divisions/Offices on the Commitment Scale ... 4-7

4.3.4 Differences Between Staff Classifications on the Commitment Scale . 4-8

4.3.5 Differences Between Supervisory Levels on the Commitment Scale . 4-8

4.4 Cohesion Scale $\ldots \ldots \ldots \ldots \ldots \ldots \ldots \ldots \ldots \ldots \ldots \ldots \ldots \ldots$

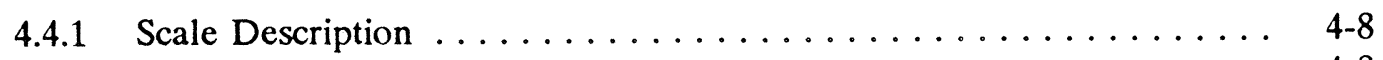

4.4 .2 Overall SERI Results ..................... 4-8

4.4.3 Differences Between Divisions/Offices on the Cohesion Scale . . . . . . 4-8

4.4.4 Differences Between Staff Classifications on the Cohesion Scale . . . . 4-8

4.4.5 Differences Between Supervisory Levels on the Cohesion Scale .... 4-8 
CONTENTS (Continued)

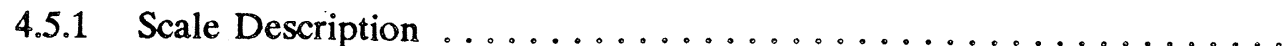

4.5 .2 Overall SERI Results . . . . . . . . . . . . . . . . . . . . .

4.5.3 Differences Between Divisions/Offices on the Coordination Scale ....

4.5.4 Differences Between Staff Classifications on the Coordination Scale ..

4.6 Job Satisfaction

4.6.1 Description of Scale $\ldots \ldots \ldots \ldots \ldots \ldots \ldots \ldots \ldots \ldots \ldots . \ldots \ldots$ 4.9. . . . . . .

4.6 .2 Overall SERI Results . . . . . . . . . . . . . . . . . . 4 4

4.6.3 Differences Between Divisions/Offices on the Job Satisfaction Scale . . 4-9

4.6.4 Differences Between Staff Classifications on the Job Satisfaction

Scale ... . . . . . . . . . . . . . . . . . . . . . . 4-10

4.6.5 Differences Between Supervisory Levels on the Job Satisfaction Scale 4-10

$4.7 \quad$ Hazard Scale $\ldots \ldots \ldots \ldots \ldots \ldots \ldots \ldots \ldots \ldots \ldots \ldots \ldots \ldots \ldots$

4.7.1 Scale Description $\ldots \ldots \ldots \ldots \ldots \ldots \ldots \ldots \ldots \ldots \ldots \ldots \ldots$ 4-10

4.7 .2 Overall SERI Results . . . . . . . . . . . . . . . . . . . . 4-10

4.7.3 Differences Between Divisions/Offices on the Hazard Scale . . . . . . . 4-10

4.7.4 Differences Between Staff Classifications on the Hazard Scale . . . . . 4-11

4.7.5 Differences Between Supervisory Levels on the Hazard Scale . . . . . . 4-11

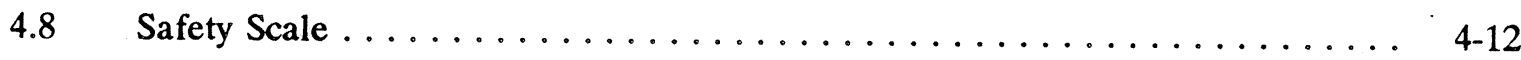

4.8.1 Scale Description ....................... 4-12

4.8 .2 Overall SERI Results $\ldots \ldots \ldots \ldots \ldots \ldots \ldots \ldots \ldots \ldots \ldots \ldots \ldots$ 4. $\ldots \ldots \ldots$. 12

4.8.3 Differences Between Divisions/Offices on the Safety Scale ... . . . . 4-12

4.8.4 Differences Between Staff Classifications on the Safety Scale ...... . 4-12

4.8.5 Differences Between Supervisory Levels on the Safety Scale . . . . . . . 4-12

4.9 Environment, Safety, and Health Questions $\ldots \ldots \ldots \ldots \ldots \ldots \ldots \ldots$ 4-12

4.9.1 Question Descriptions $\ldots \ldots \ldots \ldots \ldots \ldots \ldots \ldots \ldots \ldots \ldots$ 4-12

4.9 .2 Overall SERI Results . . . . . . . . . . . . . . . . . . 4 4-13

4.9.3 Differences Between Divisions/Offices on the Environment, Safety, and Health Questions ........................ 4 4-13

4.9.4 Jifferences Between Staff Classifications on the Environment, Safety, and Health Questions

4.9.5 Differences Between Supervisory Levels on the Environment, Safety

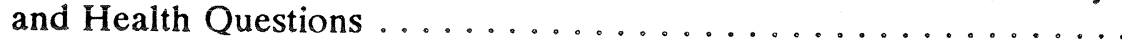


CONTENTS (Continued)

$\underline{\text { Page }}$

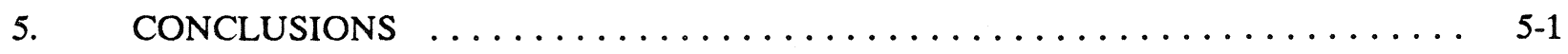

6. REFERENCES $\ldots \ldots \ldots \ldots \ldots \ldots \ldots \ldots \ldots \ldots \ldots \ldots \ldots \ldots \ldots \ldots \ldots$

APPENDIX A: SIGNIFICANT DIFFERENCES BETWEEN DIVISIONS/OFFICES

ON OCA SCALES ........................ A-1

APPENDIX B: SIGNIFICANT DIFFERENCES BETWEEN STAFF CLASS-

IFICATIONS ON OCA SCALES $\ldots \ldots \ldots \ldots \ldots \ldots \ldots \ldots$ B-1

APPENDIX C: SIGNIFICANT DIFFERENCES BETWEEN SUPERVISORY

LEVELS ON OCA SCALES ................... C-1

APPENDIX D: COMPARISON OF SERI DIVISIONS/OFFICES TO OVERALL

SERI MEAN VALUES ON OCI SCALES $\ldots \ldots \ldots \ldots \ldots \ldots \ldots \ldots \ldots$

APPENDIX E: COMPARISON OF SERI DIVISIONS/OFFICES TO OVERALL

SERI MEAN VALUES ON COMMUNICATION SCALES . . . . . . . E

APPENDIX F: COMPARISON OF SERI DIVISIONS/OFFICES TO OVERALL SERI MEAN VALUES ON ADDITIONAL SCALES $\ldots \ldots \ldots \ldots \ldots$ F-1

APPENDIX G: COMPARISON OF SERI DIVISIONS/OFFICES TO OVERALL SERI MEAN VALUES ON ENVIRONMENT, SAFETY AND

HEALTH QUESTIONS $\ldots \ldots \ldots \ldots \ldots \ldots \ldots \ldots \ldots \ldots$ G- 


\section{LIST OF FIGURES}

$\underline{\text { Page }}$

means for SERI on the OCI scales $\ldots \ldots \ldots \ldots \ldots . \ldots \ldots$ 4-4

4.1 Overall means for SERI on the OCI scales $\ldots \ldots$. . . . . . . . . . 4.5

4.2 Significant differences between staff classifications on the con

4.3 Overall means for SERI on the communication scales $\ldots \ldots \ldots \ldots \ldots \ldots \ldots \ldots \ldots \ldots$

4.4 Overall means for SERI on the additional scales $\ldots \ldots \ldots$. $\ldots . . . .4$

4.5 Significant differences between divisions/offices on the job satisfaction scale $\ldots . . .440$

4.6 Significant differences between divisions/offees on the hazard scale . . . . . . . . 4-11

4.7 Significant differences between divisions/offces on the hazard scale $\ldots \ldots \ldots \ldots 4-11$

4.8 Significant differences between staff classifications on thealth questions . . . . . . 4-13

4.9 Overall means for SERI on the environment, safety and offsite consequences question . 4-14

4.10 Significant differences between divisions/offices on the onsite consequences question . 4-14 


\section{LIST OF TABLES}

Page

3.1 Response Rates by Division/Office for SERI $\ldots \ldots \ldots \ldots \ldots \ldots \ldots \ldots \ldots \ldots$ 3-1

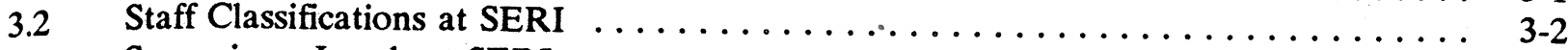

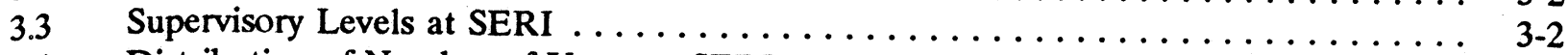

3.4 Distribution of Number of Years at SERI $\ldots \ldots \ldots \ldots \ldots \ldots \ldots \ldots \ldots \ldots \ldots \ldots \ldots$

3.5 Distribution of Educational Levels at SERI $\ldots \ldots \ldots \ldots \ldots \ldots \ldots \ldots \ldots \ldots \ldots . \ldots \ldots$

3.6 Modal Educational Level and Mean Number of Years at SERI by Division/Office ... 3- 3-4 


\section{ACRONYMS}

DOE Department of Energy

SERI Solar Energy Research Institute

Divisions/Offices

$\begin{array}{ll}\text { ADM } & \text { Administrative Services Division } \\ \text { DIR } & \text { Director's Office (Legal Office, Technical Transfer, DCO) } \\ \text { EEA } & \text { Energy and Environmental Analysis Division } \\ \text { ESH } & \text { Environment, Safety, and Health } \\ \text { FCE } & \text { Fuels and Chemicals Research and Engineering Division } \\ \text { MSE } & \text { Materials Science and Engineering Division } \\ \text { MIT } & \text { Mechanical and Industrial Technology Division } \\ \text { TSD } & \text { Technical Services Division }\end{array}$

Supervisory Levels

SUP Supervisors

NSU Non-Supervisors

$\underline{\text { Staff Classifications }}$

MGT Management

ADM Administration

RES Research (Scientist or Engineer)

NEX Non-exempt

TEC Technician

OTH Other (temporaries, post-docs, visitor, students)

Survey Scales

$\begin{array}{ll}\text { C1 } & \text { Humanistic-Encouraging } \\ \text { C2 } & \text { Affiliative } \\ \text { C3 } & \text { Approval } \\ \text { C4 } & \text { Conventional } \\ \text { C5 } & \text { Dependent } \\ \text { C6 } & \text { Avoidance } \\ \text { C7 } & \text { Oppositional } \\ \text { C8 } & \text { Power } \\ \text { C9 } & \text { Competitive } \\ \text { C10 } & \text { Perfectionistic } \\ \text { C11 } & \text { Achievement } \\ \text { C12 } & \text { Self-Actualizing }\end{array}$


ACRONYMS (Continued)

Survey Scales (Continued)

ACCURACY (CMA)

AWARENESS (EMA)

COHESION $(\mathrm{COH})$

COMMITMT (COT)

COORD (COD)

EMPHASIS (MGE)

HAZARD (HAZ)

INTERACT (CMI)

JOBSAT (JOB)

OFFSITE (OFF)

ONSITE (ONS)

SAFETY (SAF)

SATISFAC (CMS)

TRUST (CMT)
Perceived Accuracy of Communications

Employee Awareness of Workplace Hazards

Cohesion of Work Group

Organizational Commitment

Coordination

Management Emphasis of Environmental Issues

Perceived Hazardous Nature of Work

Desirability of Interaction with Others

Overall Job Satisfaction

Consequence to Offsite Environment

Consequence to Onsite Environment

Attention to Safety

Satisfaction with Communications

Trust in Communications 


\section{ACKNOWLEDGEMENT}

The authors wish to thank the Department of Energy (DOE) staff that have been supportive and facilitative of this work, Mark Gilbertson, Frank Tooper, and Larry Weiner, as well as the Solar Energy Research Institute (SERI) for their cooperation in this effort, in particular, Gary Nuss, for his help in arranging the logistics and details of the survey administration.

We also extend our appreciation to the efforts of our Brookhaven National Laboratory colleague, John Usher, for his help in administering the survey, David Stock, for his statistical assistance and expertise, Sonja Santos, for her proficiency in graph production, and Kathleen Nasta for her help in preparing this manuscript. In addition, the review, comments, and insights provided by James Higgins were also very much appreciated. 


\section{INTRODUCTION}

An Organizational Cultural Assessment (OCA) was performed at the Solar Energy Research Institute (SERI) by administering an Organizational Culture Survey (OCS) that queried employees on work group cohesion, coordination, various aspects of communication, employee commitment to SERI, and overall job satisfaction. below.

The primary purpose of administering the survey was to attempt to measure, in a quantitative and objective way the notion of "organizational culture," that is, the values, attitudes, and beliefs of the which are working within the organization. In particular, those aspects of the working environment relevant to the organization were assessed.

In addition, by conducting a survey, a broad sampling of the individuals in the organization can be obtained. This is especially important when the survey is utilized in conjunction with an assessment or inspection team which typically has only a limited amount of resources to address many issues. The OCS provides a broad and comprehensive picture of the organization by querying a much larger number of individuals than could be reached through the assessment team alone.

Finally, the OCS provides a descriptive profile of the organization at one point in time. This profile can then be used as a baseline point against which comparisons of other points in time can be made. Such comparisons may prove valuable and would help to assess changes in the organizational
culture. Comparisons of profiles can also be 


\section{METHODOLOGY}

The Organizational Culture Survey (OCS) was administered to the employees of SERI in large groups. The surveys were administered on June 25 and 26, 1991. Included with the survey was a cover letter explaining the purpose for the survey administration. Prior to the survey administration, a memorandum from the Director's Office at SERI was circulated. This memorandum encouraged employees to complete the survey and contained the times at which various groups of employees were to take the survey. A demographics sheet attached to the survey requested information pertaining to the division/office in which the respondent was located, the number of years they had been working at SERI, their staff classification, and their supervisory and educational levels.

A person familiar with the OCS was at SERI during the survey administration in order to distribute the surveys and to answer any questions employees had. A total of 492 surveys were completed, for a response rate of 85.1 percent. The surveys were taken from SERI for data entry and analysis.

Overall means, standard errors, and standard deviations were computed for each scale assessed in the OCS. A one-way analysis of variance was also performed on each OCS scale using the scale score as the dependent variable and separate analyses using division/office, staff classification, and supervisory level as the independent variables. In order to control the false positive rate (Type I error rate), the Bonferroni correction was applied to all the analyses of variance performed for each independent variable. Since there were 26 one-way analyses of variance for each independent variable, the significance level for each was reduced to $.05 / 26=.0019$. Where the analysis of variance showed a significant difference among the group means at the .0019 level, a Tukey HSD (Honestly Significant Difference) (Hays, 1988) procedure was applied to identify those means that were statistically significantly different from each other. Consequently, the results that are reported to be significantly different from each other represent a very conservative approach in the interpretation of the data analysis performed.

Included in this report are the overall results for SERI on each of the scales used in the OCS. In addition, any statistically significant differences between divisions/offices, staff classifications, and supervisory levels are also presented. 


\section{ORGANIZATIONAL DESCRIPTION}

The Solar Energy Research Institute (SERI) identifies its organizational units as divisions or offices. The demographics sheet used in the administration of the OCS included eight of these divisions/offices. The divisions/offices and their abbreviations, as used in this report, are presented in Table 3.1. Also presented in this table are the response rates for each division/office. The response rate is computed by dividing the number of surveys returned by the number of employees in that division/office. The highest response rate obtained was in the Administrative Services Division, the Director's Office, and the Environment, Safety, and Health Section, all of which had response rates of 100 percent, or higher. The greater than 100 percent response rate is due either to miscategorization on the part of the respondents, or an inaccurate number provided by the facility. The lowest response rate was in the Mechanical and Industrial Technology Division, which had a response rate of 62.4 percent.

Table 3.1. Response Rates by Division/Office for SERI

\begin{tabular}{|c|c|c|c|}
\hline Division/Office & No. Responses & No. Employees & Response Rate \\
\hline Administrative Services Division (ADM) & 75 & 73 & 102.7 \\
\hline $\begin{array}{l}\text { Director's Office (Legal and Technology } \\
\text { Transfer Office, DCO) (DIR) }\end{array}$ & 56 & 55 & 101.8 \\
\hline $\begin{array}{l}\text { Energy \& Environmental Analysis Divi- } \\
\text { sion (EEA) }\end{array}$ & 20 & 27 & 74.1 \\
\hline $\begin{array}{l}\text { Environment, Safety \& Health Section } \\
\text { (ESH) }\end{array}$ & 10 & 10 & 100.0 \\
\hline $\begin{array}{l}\text { Fuels \& Chemical Research \& Engineer- } \\
\text { ing Division (FCE) }\end{array}$ & 81 & 115 & 70.4 \\
\hline $\begin{array}{l}\text { Materials Science \& Engineering Division } \\
\text { (MSE) }\end{array}$ & 110 & 133 & 82.7 \\
\hline $\begin{array}{l}\text { Mechanical and Industrial Technology } \\
\text { Division (MIT) }\end{array}$ & 53 & 85 & 62.4 \\
\hline Technical Services Division (TSD) & 74 & 80 & 92.5 \\
\hline Unknown & 13 & --- & $-\cdots$ \\
\hline Total: & 492 & 578 & 85.1 \\
\hline
\end{tabular}

SERI employees were also given six staff classifications on the demographics sheet in which to categorize themselves. Table 3.2 presents these staff classifications, and their abbreviations, as used in this report. Also in this table are the percent of the sample represented by each staff classification. The Research Staff Classification represents the largest portion of the SERI sample (32.9 percent), while the Technician Staff Classification accounts for the smallest portion (8.9 percent). 
Table 3.2. Staff Classifications at SERI

\begin{tabular}{||l|r|r||}
\hline \multicolumn{1}{|c|}{ Staff Classification } & No. Responses & $\begin{array}{c}\text { Percent of } \\
\text { Total Sample }\end{array}$ \\
\hline \hline Management & 57 & 11.6 \\
\hline Administration & 110 & 22.4 \\
\hline Research (scientist or engineer) & 162 & 32.9 \\
\hline Non-exempt & 55 & 11.2 \\
\hline Technician & 44 & 8.9 \\
\hline $\begin{array}{l}\text { Other (temporaries, post-docs, visiting professionals, } \\
\text { students) }\end{array}$ & 52 & 10.6 \\
\hline Unknown & 12 & 2.4 \\
\hline
\end{tabular}

The Organizational Culture Survey (OCS) demographics questions used at SERI also provided two categories of supervisory levels by which an employee could identify him/herself. Table 3.3 presents the percent of the total sample which the two categories represent.

Table 3.3. Supervisory Levels at SERI

\begin{tabular}{||l|c|c||}
\hline \multicolumn{1}{|c|}{ Supervisory Level } & No. Responses & $\begin{array}{c}\text { Percent of } \\
\text { Total Sample }\end{array}$ \\
\hline \hline Supervisor & 126 & 25.6 \\
\hline Non-Supervisor & 356 & 72.4 \\
\hline Unknown & 10 & 2.0 \\
\hline
\end{tabular}

Table 3.4 presents information on the number of years the respondents have been at SERI. Approximately 42 percent of the respondents have been at SERI three years or less. Note, however, that the SERI sample includes 52 temporary individuals, such as students, visiting professionals, and temporary employees. Just over 24 percent of the respondents have been employed at SERI between four and nine years. Thirteen respondents, or 2.6 percent, chose not to indicate the number of years they had been at SERI.

Table 3.5 depicts the number of respondents for each educational level and the percent of the total sample by educational level that number represents for SERI. By far, the greatest number of respondents at SERI had a graduate degree (40.0 percent). 
Table 3.4. Distribution of Number of Years at SERI

\begin{tabular}{||l|r|r||}
\hline Number of Years & No. Respondents & $\begin{array}{c}\text { Percent of } \\
\text { Total Sample }\end{array}$ \\
\hline \hline$\leq 6$ months & 80 & 16.3 \\
\hline $1-3$ years & 126 & 25.6 \\
\hline $4-6$ years & 62 & 12.6 \\
\hline $7-9$ years & 59 & 12.0 \\
\hline $10-12$ years & 103 & 20.9 \\
\hline $13-15$ years & 48 & 9.8 \\
\hline $16-18$ years & 1 & 0.2 \\
\hline Unknown & 13 & 2.6 \\
\hline
\end{tabular}

Table 3.5. Distribution of Educational Levels at SERI

\begin{tabular}{|l|c|c|}
\hline \multicolumn{1}{|c|}{ Educational Level } & No. Responses & $\begin{array}{c}\text { Percent of } \\
\text { Total Sample }\end{array}$ \\
\hline \hline Some High School & 4 & 0.8 \\
\hline High School Degree & 19 & 3.9 \\
\hline Some Technical School & 10 & 2.0 \\
\hline 2-Year Technical Degree & 9 & 1.8 \\
\hline Some College & 95 & 19.3 \\
\hline 2-Year College Degree & 25 & 5.1 \\
\hline 4-Year College Degree & 74 & 15.0 \\
\hline Some Graduate Work & 49 & 10.0 \\
\hline Graduate Degree & 197 & 40.0 \\
\hline Unknown & 10 & 2.0 \\
\hline
\end{tabular}

Table 3.6 presents the modal educational level and mean number of years at SERI for the survey respondents in each division/office. Four of the eight divisions/offices have modal educational levels of a graduate degree. The Administrative and Technical Services Divisions both have modal educational levels of some college. The modal educational level for the entire SERI population is a graduate degree. These results indicate the SERI sample to be a highly educated group. The division/office with the 
shortest tenure is the Environment, Safety and Health Section, with an average length of time at SERI of 2.9 years. The Director's Office had the longest tenure at SERI, 6.56 years. The mean length of time of employment at SERI for the sample which took the survey is 5.86 years.

Table 3.6. Modal Educational Level and Mean Number of Years at SERI by Division/Office

\begin{tabular}{|l|c|r||}
\hline \multicolumn{1}{|c|}{ Division/Office } & Educational Level & No. Years \\
\hline \hline Administrative Services Division & 5 & 6.17 \\
\hline $\begin{array}{l}\text { Director's Office (Legal and Technology Transfer Office, } \\
\text { DCO) }\end{array}$ & 7 & 6.56 \\
\hline Energy \& Environmental Analysis Division & 9 & 4.53 \\
\hline Environment, Safety \& Health Section & 8 & 2.90 \\
\hline Fuels \& Chemicals Research \& Engineering Division & 9 & 5.26 \\
\hline Materials Science \& Engineering Division & 9 & 6.43 \\
\hline Mechanical \& Industrial Technology Division & 9 & 6.18 \\
\hline Technical Services Division & 5 & 5.34 \\
\hline Overall & 9 & 5.86 \\
\hline
\end{tabular}

Educational Level: $\quad 5=$ Some College; $6=2$-Year College Degree; $7=4$-Year College Degree; 8 = Some Graduate Work; $9=$ Graduate Degree. 


\section{ORGANIZATIONAL CULTURE SURVEY SCALES AND RESULTS}

The Organizational Culture Survey (OCS) administered at the Solar Energy Research Institute (SERI) was comprised of the Organizational Culture Inventory (OCI) (Human Synergistics, 1987), which consists of 12 scales, and scales which assess communication processes, commitment to the organization, cohesiveness to work group, coordination of work, overall job satisfaction, perceived hazardous nature of work, attention to safety, and questions concerning environmental issues. The results from each of these scales are discussed in the sections that follow. Each section presents the overall results for SERI on that scale(s), the results by division/office, by staff classification, and by supervisory level.

\subsection{Organizational Culture Inventory}

\subsubsection{Description}

The philosophy of management, the mission of the organization, and the strategic choices management makes determine the culture of the organization (Cooke and Burack, 1987). The aspect of culture most immediately affected by these factors is what is valued by the organization. The extent to which these values are recognized and shared reflects the strength of the organization's culture. Organizational factors, along with these shared values, influence the operating structures of the organization, its human resource management practices, and the styles of its supervisors. To the extent that these shared values and behavioral norms can be measured and evaluated, data collection of this type is important in understanding the organizational factors that influence performance.

The Organizational Culture Inventory (OCI) (Human Synergistics, 1987) is a paper-and-pencil diagnostic system for measuring the aspects of organizational culture that have the greatest impact on the activities of members and the functioning of the organization. Respondents are asked to review 120 statements which describe some of the thinking and behavioral styles that members of an organization may be expected to adopt in carrying out their work and in interacting with others. These statements comprise 12 different cultural scales, some of which are indicative of a positive and supportive environment, while others are useful in identifying potentially dysfunctional environments. All of the scales measured by the $\mathrm{OCI}$ are related to, and result from, organizational structural variables, reward systems, managerial styles and philosophies, and other factors that can be changed, at least to some extent, by those in leadership positions.

The 12 organizational culture scales, with examples of the items used to assess each one, are described below. For a complete listing of the OCI scale items, see Human Synergistics (1987).

C1: HUMANISTIC-ENCOURAGING: Organizations which are managed in a participative and personcentered way. Members are expected to be supportive, constructive, and open to influence in their dealings with one another.

- Involving subordinates in decisions;

- Showing concern for the needs of others;

- Giving positive rewards to others.

C2: AFFILIATIVE: Organizations which place a high priority on constructive personal relations. The members are expected to be friendly, open, and sensitive to the satisfaction of their work group.

- Thinking in terms of the group's satisfaction; 
- Using good human relations skills;

- Motivating others with friendliness.

C3: APPROVAL: Organizations in which conflicts are avoided and personal relations are pleasant, at least superficially. Members feel they should agree with and gain approval of others.

- Staying on the good side of superiors;

- Making sure people accept you;

- Setting goals that please others.

C4: CONVENTIONAL: Organizations that are conservative, traditional, and bureaucratically controlled. Members are expected to conform, follow rules, and make a good impression.

- Always following policies and practices;

- Avoiding confrontations;

- Fitting into the "mold."

C5: DEPENDENT: Organizations that are hierarchically controlled and non-participative. Centralized decision making leads members to do only what they are told and to clear all decisions with superiors.

- Accepting goals without questioning them;

- Never challenging superiors;

- Willingly obeying orders.

C6: AVOIDANCE: Organizations that do not reward success but punish failure. Negative rewards lead members to shift responsibility to others and avoid being blamed for mistakes.

- Taking few chances;

- Laying "low" when things get tough;

- Pushing decisions upward.

C7: OPPOSITIONAL: Organizations in which confrontation prevails and negativism is rewarded. Members gain status and influence by being critical and are encouraged to oppose the ideas of others.

- Pointing out flaws;

- Remaining aloof from the situation;

- Playing the role of the "loyal opposition".

C8: POWER: Non-participative organizations which are structured on the basis of authority in members' positions. Members expect to take charge, control subordinates, and respond to demands of superiors.

- Demanding loyalty;

- Acting forceful;

- Maintaining unquestioned authority.

C9: COMPETITION: Organizations where winning is valued and rewards are given for out-performing others. Members operate in a "win-lose" framework and work against their peers to be noticed. 
- Always trying to be right;

- Out-performing one's peers;

- Turning the job into a contest.

C10: PERFECTIONISTIC: Organizations in which persistence, hard work, and perfectionism are highly valued. Members feel they must avoid all mistakes, keep track of everything, and work long hours to attain specific objectives.

- Setting unrealistically high goals;

- Viewing work as more important than anything else;

- Persisting, enduring.

C11: ACHIEVEMENT: Organizations that do things well and value members who set and accomplish their own goals. Members set challenging, but realistic goals, and plan and pursue them with enthusiasm.

- Exploring alternatives before acting;

- Pursuing a standard of excellence;

- Openly showing enthusiasm.

C12: SELF-ACTUALIZING: Organizations that value creativity, quality over quantity, tasks, and individual growth. Members are encouraged to gain satisfaction from their work, develop themselves, and take on new activities.

- Thinking in unique and independent ways;

- Communicating ideas;

- Being spontaneous.

From these twelve scales, three cultural styles are described. The first style is comprised of the Humanistic-Encouraging (C1), Affiliative (C2), Achievement (C11), and Self-Actualizing (C12) Scales. These scales are considered "Constructive Styles;" in other words, organizations which score high on these four scales tend to promote behaviors which are conducive to the satisfaction of the organizational members.

The second cultural style is the "Passive/Defensive Style." This style is made up of the Approval (C3), Conventional (C4), Dependent (C5), and Avoidance (C6) Scales. In organizations which score high on these scales, a culture exists which leads employees of the organization to act and react in a defensive way and at the same time, act in a way which does not pose a threat to one's own security within that organization.

A third cultural style is made up of the Oppositional (C7), Power (C8), Competitive (C9), and Perfectionistic (C10) Scales. Organizations which score high on these scales often expect members to act in a way that is forceful and that protects one's position and status. In other words, members adopt an "Aggressive/Defensive Style" in order to be successful within the organization.

\subsubsection{Overall Profile}

The overall mean scores on the OCI scales for the entire sample of SERI employees who responded to the Organizational Culture Survey (OCS) are depicted in Figure 4.1. The scales are 
identified by number and are described in the preceding section. The scores represent the mean score for the entire sample where the score 1 equals not at all and the score 5 equals to a great extent.

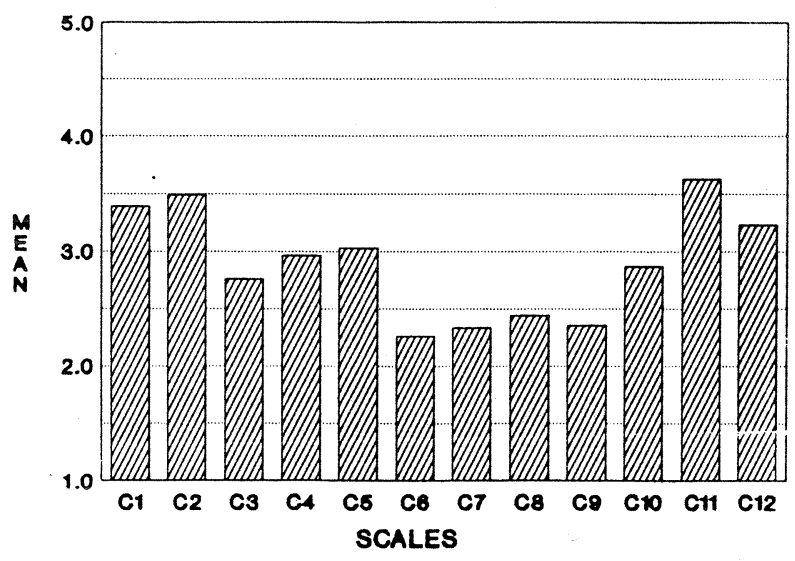

Figure 4.1. Overall means for SERI on the OCI scales

As seen in Figure 4.1, based on the sample of SERI employees who responded to the OCS, the organizational profile is best described by the constructive cultural style on the $\mathrm{OCI}$, as represented by the high mean scores on the Humanistic-Encouraging, Affiliative, Achievement, and Self-Actualizing (C1, C2, C11, and C12) Scales. The highest mean score occurred on the Achievement Scale. Additionally, the respondents perceived the organization to be hierarchically managed and controlled, as evidenced by the mean score on the Dependent Scale (C5). The organization tends to be approval seeking (C3), conservative (C4) and perfectionistic (C10). Thus, SERI appears to be a constructive organization, with employees who tend to behave in a defensive, but not aggressive manner, as demonstrated by the lower mean scores on the Oppositional, Power, and Competitive (C7, C8, C9) scales.

\subsubsection{Differences Between Divisions/Offices on the OCI}

No statistically significant differences between divisions/offices at SERI were obtained on any of the OCI Scales. Appendix A contains the mean values for each division/office on each of the scales. In addition, Appendix D contains figures which compare the mean values obtained on each OCI scale for each division/office to the overall mean value for SERI.

\subsubsection{Differences Between Staff Classifications on the OCI}

Statistically significant differences between staff classifications were obtained on only one scale of the OCI. However, Appendix B presents the mean values for each staff classification on each scale. The scale on which differences were obtained is the Conventional (C4) Scale. The results are presented in Figure 4.2. On this scale, the Other Staff (i.e., Temporaries, Post-Docs, Visitors, Students) were statistically significantly less conventional than the Technicians, Non-Exempt, and Administration Staff Classification. The Management Staff had a statistically significantly lower mean score on this scale than the Technician Staff Classification. No other statistically significant differences between SERI Staff Classifications were obtained on this scale. 


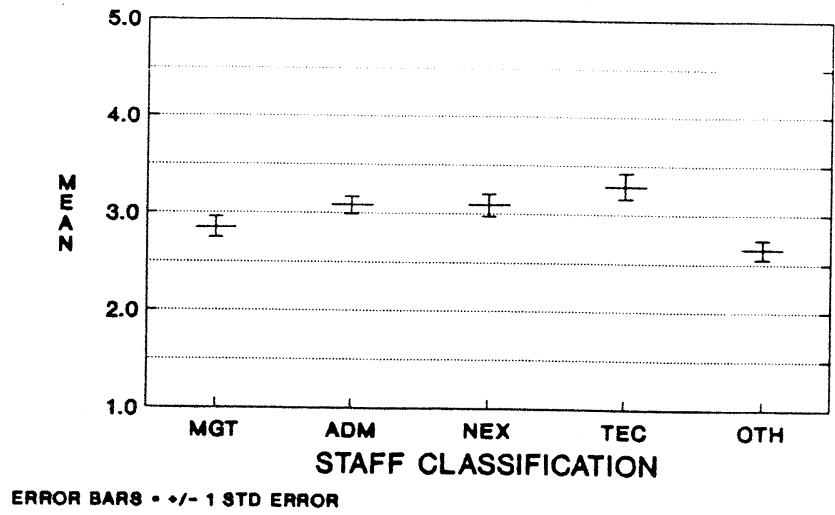

Figure 4.2. Significant differences between staff classifications on the conventional scale

\subsubsection{Differences Between Supervisory Levels on the OCI}

No statistically significant differences were obtained between the Supervisor Levels at SERI on the OCI Scales. Appendix C contains the mean values for the supervisory levels on each scale.

\subsection{Communication Scales}

\subsubsection{Description}

Communication is a critical process for effective operations in any organization. However, because it is a process rather than a variable, it is very difficult to measure. The scales used in the questionnaire administered at SERI were developed by Roberts and O'Reilly (1974). They have been administered to various organizations with good reliability and success in analyzing several facets of the communication process.

Four communication scales were administered and are described below. The range on each scale is from a low score of 1 to a high score of 7 .

TRUST: $\quad$ Freedom to discuss the problems and difficulties in the job with an immediate supervisor without jeopardy.

ACCURACY: Perception of the accuracy of information received from other organizational levels (superior, same, and subordinate levels).

INTERACT: Desirability of frequent contact with others in the organization (superiors, same, and subordinates).

SATISFAC: Overall satisfaction with the communication process in the organization.

\subsubsection{Overail SERI Resuits}

The overall means for SERI on each of the communication scales described above are presented in Figure 4.3. All four scales have relatively high mean values. SERI employees desire a high level of 
interaction with others across the organization and perceive the information they receive from others to be accurate. SERI employees also trust their superiors and are satisfied with the overall communication process at SERI.

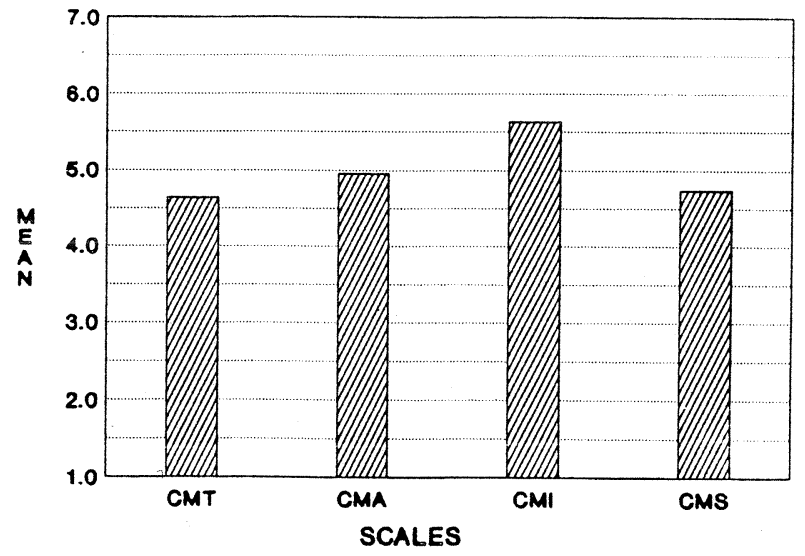

Figure 4.3. Overall means for SERI on the communication scales

\subsubsection{Differences Between Divisions/Offices on the Communication Scales}

No statistically significant differences between divisions/offices were obtained on any of the communication scales. The reader is referred to Appendix $A$ for the mean values for each division/office on each of the communication scales. In addition, Appendix E contains figures which compare each division/office to the overall mean value of the SERI sample on each of the communication scales.

\subsubsection{Differences Between Staff Classifications on the Communication Scales}

No statistically significant differences between staff classifications were obtained on any of the four communication scales. Appendix B contains the mean values obtained for each staff classification on each communication scale.

\subsubsection{Differences Between Supervisory Levels on the Communication Scales}

No statistically significant differences between supervisory levels at SERI were obtained on any of the communication scales. Appendix $\mathrm{C}$ contains the mean values obtained for the two supervisory levels on each communication scale.

\subsection{Commitment Scale}

\subsubsection{Scale Description}

The Commitment Scale is defined as the relative sirength of an individual's identification with and involvement in a particular organization (Mowday \& Steers, 1979). This commitment extends to the goals of the organization and the desire to maintain membership in the organization to facilitate these goais. The range on this scale is from a low score of 1 (low commitment) to a high score of 7 (high commitment). 


\subsubsection{Overall SERI Results}

The mean score for the SERI sample on the Commitment Scale was 5.11, as depicted in Figure 4.4. Mean scores for additional scales are also shown in this figure and will be discussed later. Employees of SERI who responded to the survey appear to be committed to the organization.

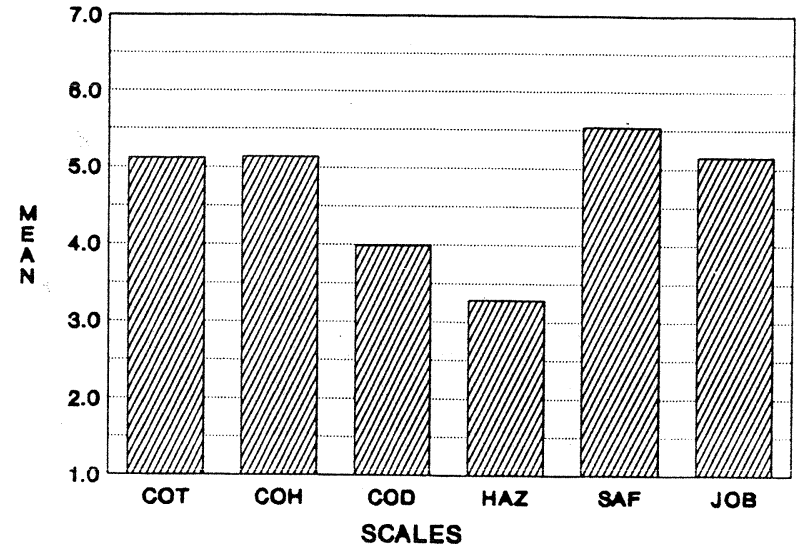

Figure 4.4. Overall means for SERI on the additional scales

\subsubsection{Differences Between Divisions/Offices on the Commitment Scale}

Statistically significant differences between divisions/offices on the Commitment Scale are depicted in Figure 4.5. The Environment, Safety, and Health Section had the highest mean value on this scale and was statistically significantly different from the Administrative Services Division. No other statistically significant differences between divisions/offices were obtained on this scale.

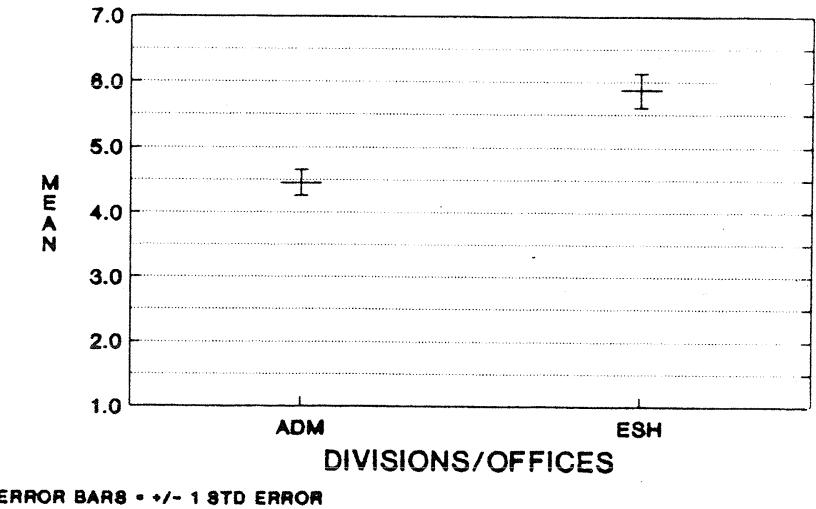

Figure 4.5. Significant differences between divisions/offices on the commitinent scale

Appendix $\mathrm{F}$ contains figures which compare each division/office to the overall mean value of the SERI sample for each of the scales contained in Figure 4.4. 


\subsubsection{Differences Between Staff Classifications on the Commitment Scale}

No significant differences were obtained between any of the staff classifications on the Commitment Scale. Appendix B contains the mean value for each staff classification on this scale.

\subsubsection{Differences Between Supervisory Levels on the Commitment Scale}

No significant differences were obtained between the two supervisory levels on the Commitment Scale. Appendix $\mathrm{C}$ contains the mean value for each supervisory level on this scale.

\subsection{Cohesion Scale}

\subsubsection{Scale Description}

The Cohesion Scale is very similar to the Commitment Scale except that it is defined as the relative strength of an individual's identification with and involvement in a particular work group (Seashore, 1954; Price \& Muller, 1972). The range on this scale is from a low score of 1 (weak cohesiveness) to a high score of 7 (strong cohesiveness).

\subsubsection{Overall SERI Results}

The overall mean score for the SERI sample on the Cohesion Scale was 5.14 (Figure 4.4), essentially equivalent to the mean score for the sample on the Commitment Scale. In general, employees of SERI who responded to the survey identify with their own work groups as much as they do with the overall organization.

\subsubsection{Differences Between Divisions/Offices on the Cohesion Scale}

No statistically significant differences between divisions/offices at SERI were obtained on the Cohesion Scale. Appendix A contains the mean values for each division/office on this scale.

\subsubsection{Differences Between Staff Classifications on the Cohesion Scale}

No statistically significant differences between any staff classifications were obtained on the Cohesion Scale. Appendix B contains the mean values for each staff classification on the Cohesion Scale.

\subsubsection{Differences Between Supervisory Levels on the Cohesion Scale}

No statistically significant differences between supervisory levels were obtained on the Cohesion Scale. Appendix $\mathrm{C}$ contains the mean values for each supervisory level on this scale.

\subsection{Coordination Scale}

\subsubsection{Scale Description}

The Coordination Scale assesses the employee's perception of the degree to which the subunits of an organization operate according to the requirements of each other and of the total organization 
(Georgopoulos \& Mann, 1962). The range on this scale is from a low score of 1 (low coordination) to a high score of 7 (high coordination).

\subsubsection{Overall SERI Results}

The overall mean score on this scale for the SERI sample was 3.99 (see Figure 4.4). This indicates that SERI personnel perceive a moderate amount of coordination to exist between the work activities in their organization.

\subsubsection{Differences Between Divisions/Offices on the Coordination Scale}

No statistically significant differences between SERI divisions/offices were obtained on this scale. The mean values obtained on this scale for each of SERI's divisions/offices are contained in Appendix A.

\subsubsection{Differences Between Staff Classifications on the Coordination Scale}

No statistically significant differences between staff classifications were found on the Coordination Scale. Appendix B contains the mean values for each staff classification at SERI on this scale.

\subsubsection{Differences Between Supervisory Levels on the Coordination Scale}

No significant differences between supervisory levels were found on the Coordination Scale at SERI. Appendix C contains the mean values for each supervisory level on this scale.

\subsection{Job Satisfaction}

\subsubsection{Description of Scale}

The Job Satisfaction Scale (Kunin, 1955) refers to employees' overall satisfaction with their jobs. While it is not able to point to specific aspects of the working environment which people are satisfied or dissatisfied with, it can help to determine if employee satisfaction is something which needs further consideration by management. The scale ranges from a low score of 1 (very dissatisfied) to a high score of 7 (very satisfied).

\subsubsection{Overall SERI Results}

Overall, SERI employees tended to be satisfied with their jobs. The mean value for the SERI sample on this scale was 5.15 (see Figure 4.4).

\subsubsection{Differences Between Divisions/Offices on the Job Satisfaction Scale}

Statistically significant differences between SERI divisions/offices on the Job Satisfaction Scale are shown in Figure 4.6. The Administrative Services Division had a statistically significantly lower mean value on this scale than the Environment, Safety, and Heaith Section. No other statistically significant differences between divisions/offices at SERI were obtained on this scale. 


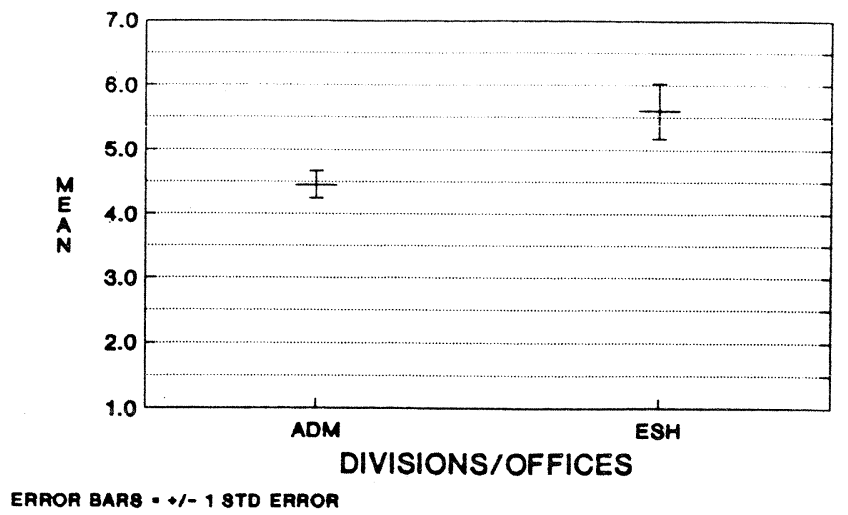

Figure 4.6. Significant differences between divisions/offices on the job satisfaction scale

\subsubsection{Differences Between Staff Classifications on the Job Satisfaction Scale}

No statistically significant differences between staff classifications were obtained on the Job Satisfaction Scale for the SERI sample. Appendix B contains the mean values for each staff classification on this scale.

\subsubsection{Differences Between Supervisory Levels on the Job Satisfaction Scale}

No statistically significant differences between the supervisory levels were obtained at SERI on the Job Satisfaction Scale. Appendix C contains the mean values for each level on this scale.

\subsection{Hazard Scale}

\subsubsection{Scale Description}

The Hazard Scale is used to identify people's perception of the hazardous nature of their work (K.H. Roberts, 1990, personal communication). The scale ranges from a low score of 1 (not hazardous) to a high score of 7 (very hazardous).

\subsubsection{Overall SERI Results}

The overall SERI mean score on this scale was 3.28 (see Figure 4.4). This indicates that employees at SERI perceive some, but not a high amount of hazard in their work.

\subsubsection{Differences Between Divisions/Offices on the Hazard Scale}

The statistically significant differences between divisions/offices at SERI are depicted in Figure 4.7. Every division/office was statistically significantly different from at least two other divisions/offices on the Hazard Scale. The Environment, Safety, and Health Section had the highest mean value on this scale and, along with the Fuels and Chemicals Research and Engineering Division, and the Materials Science and Engineering Division, was statistically significantly different from the Administrative Services Division, the Energy and Environmental Analysis Division, and the Director's Office. The Director's 
Office had the lowest mean value on this scale. Other statistically significant differences between divisions/offices at SERI on the Hazard Scale are given in Appendix A.

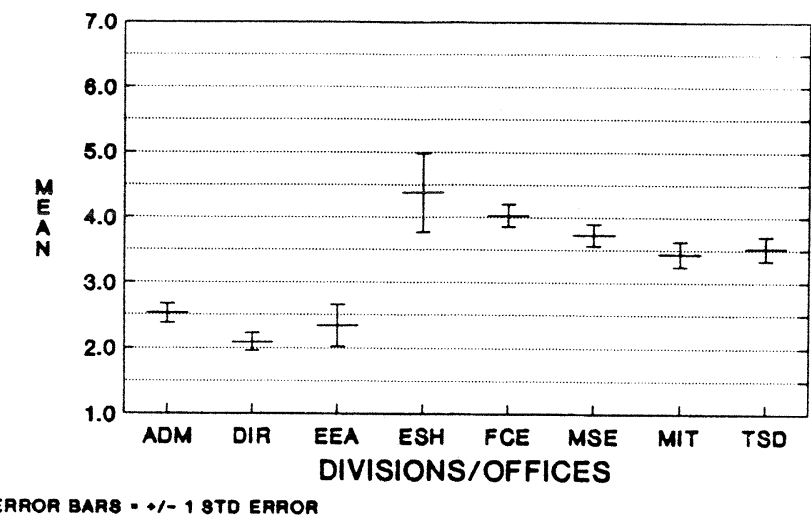

Figure 4.7. Significant differences between divisions/offices on the hazard scale

\subsubsection{Differences Between Staff Classifications on the Hazard Scale}

As shown in Figure 4.8, statistically significant differences on the Hazard Scale were obtained between every staff classification. The Technician Staff Classification scored the highest on this scale, and was statistically significantly higher than the Management, Administration, and Non-Exempt Staff Classifications. The Administration Staff Classification scored the lowest on this scale, and was significantly different from the Research (Scientist or Engineer), Technician, and the Other Staff Classifications. Other statistically significant differences between staff classifications on the Hazard Scale are reported in Appendix B.

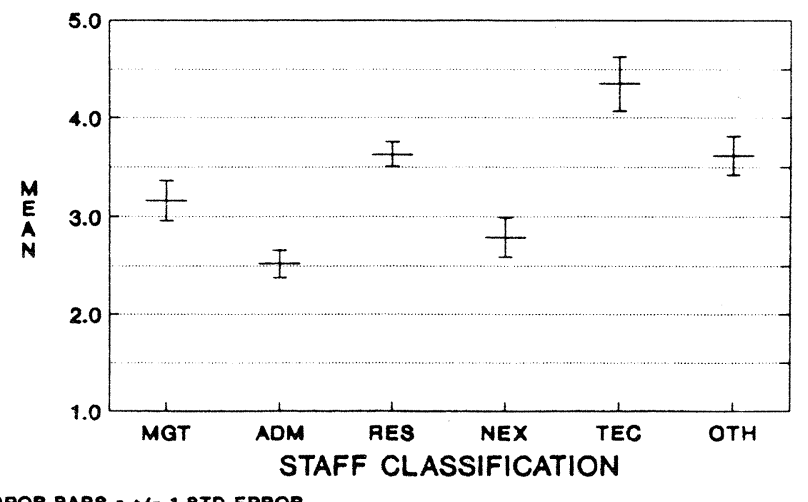

Figure 4.8. Significan ${ }_{\mathfrak{\imath}}$ differences between staff classifications on the hazard scale

\subsubsection{Differences Between Supervisory Levels on the Hazard Scale}

No statistically significant differences were obtained on the Hazard Scale between supervisory levels at SERI. Appendix C presents the mean values for each level on this scale. 


\subsection{Safety Scale}

\subsubsection{Scale Description}

The Safety Scale, developed by researchers at the University of California at Berkeley (K. H. Roberts, 1989, personal communication), is used to assess an individual's perception of the importance of safety to success in an organization. Safety is defined as operating in a manner to ensure that the probability of making a mistake is low, because the consequence of making a mistake is high. Organizations typically viewed as operating in this manner are nuclear reactors, naval aircraft carriers and air traffic control centers. The safety scale consists of 40 items which range from a low score of 1 (does not help at all) to a high score of 7 (helps a great deal).

\subsubsection{Overall SERI Results}

The overall mean score for the SERI sample on the Safety Scale was 5.54 (see Figure 4.4), indicating that employees of SERI do understand those behaviors which are important to safe operations.

\subsubsection{Differences Between Divisions/Offices on the Safety Scale}

No statistically significant differences between divisions/offices at SERI were obtained on the Safety Scale. The mean values for each division/office on this scale are presented in Appendix A.

\subsubsection{Differences Between Staff Classifications on the Safety Scale}

No statistically significant differences between staff classifications on the Safety Scale were obtained at SERI. Appendix B presents the mean values for each staff classification on this scale.

\subsubsection{Differences Between Supervisory Levels on the Safety Scale}

No statistically significant differences between supervisory levels were obtained at SERI on the Safety Scale. Appendix C presents the mean values for each supervisory level on this scale.

\subsection{Environment, Safety, and Health Questions}

\subsubsection{Question Descriptions}

For the administration of the Organizational Culture Survey (OCS) at SERI, four questions pertaining to environment, safety, and health (ES\&H) issues were used. Each question ranges from a low score of 1 (not at all or little) to a high score of 7 (very likely or a lot).

The first ES\&H question deals with the likelihood of serious offsite environmental damages/consequences due to improper or substandard performance by a work group. The second ES\&H question deals with the likelihood of serious onsite nvironmental damages/consequences due to improper or substandard performance by a work group. The third ES\&H question asks employees to assess the amount of emphasis they believe management places on environmental issues. Finally, the fourth ES\&H question asks employees for their perception of how well informed they are of possible risks in their work environment. 


\subsubsection{Overall SERI Results}

For the first ES\&H question, a mean value of 2.24 (Figure 4.9) was obtained for the SERI sample. SERI employees do not believe that if improper or substandard work was produced by their working group that a potential for serious offsite environmental consequences would exist.

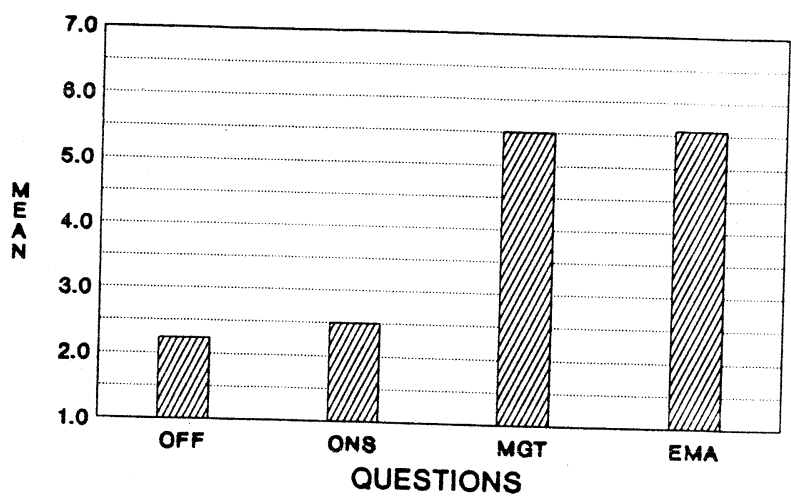

Figure 4.9. Overall means for SERI on the environment, safety and health questions

The mean value for the SERI sample on the second question was 2.51 (Figure 4.9). This mean is slightly higher than the mean obtained on the first question, indicating that while SERI employees do not believe there to be a large potential for onsite environmental consequences due to improper or substandard performance in their working groups, the potential for onsite damages to the environment is perceived to be greater than the potential for offsite environmental damages.

The mean value obtained for the third ES\&H question was 5.51 (Figure 4.9). SERI employees believe management places a high amount of emphasis on environmental issues.

The mean value obtained for the fourth ES\&H question was 5.57, slightly higher than the previous question (Figure 4.9). SERI employees believe themselves to be well informed concerning the
risks in their

\subsubsection{Differences Between Divisions/Offices on the Environment, Safety, and Health Questions}

Statistically significant differences were obtained between divisions/offices on two of the four ES\&H questions. As shown in Figure 4.10, the Environment, Safety, and Health Section had the highest mean value on the first ES\&H question and was statistically significantly different from every other SERI division/office on the issue of potential offsite environmental consequences as a function of improper or substandard performance of their work group. The Director's Office had the lowest mean Safety, and Health Section addition to being statistically significantly different from the Environment, Research and Engineering Division. No sther statistically different from the Fuels and Chemicals sions/offices at SERI existed on this question. 


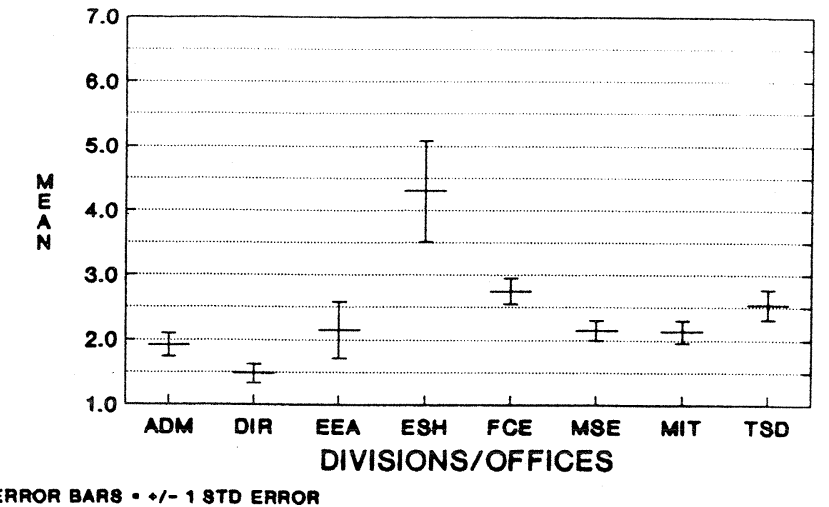

Figure 4.10. Significant differences between divisions/offices on the offsite consequences question

Statistically significant differences between SERI divisions/offices were also obtained on the question concerning the amount of onsite environmental damages/consequences which could occur as a function of substandard performance by the work group (Figure 4.11). The Environment, Safety, and Health Section had the highest mean value on this question and was statistically significantly different from every other division/office at SERI other than the Fuels and Chemicals Research and Engineering Division. The Fuels and Chemicals Research and Engineering Division had a statistically significantly higher mean value on this question than the Administrative Services Division, the Energy and Environmental Analysis Division, and the Director's Office. The Director's Office had the lowest mean value on this question. No other statistically significant differences between divisions/offices on this question were obtained.

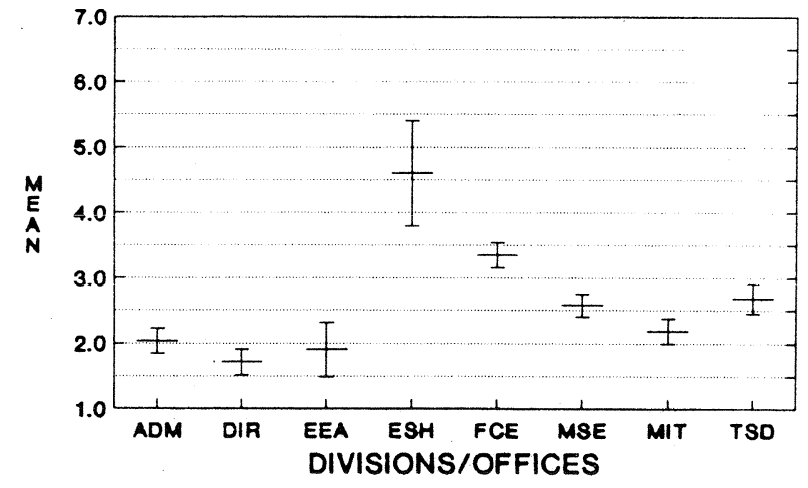

ERAOR BAR8 * $\because-1$ STD ERAOR

Figure 4.11. Significant differences between divisions/offices on the onsite consequences question

Appendix A contains the mean values for each division/office on each of the two ES\&H questions in which no statistically significant differences were present. Appendix $G$ contains figures which compare the mean value of each division/office to the overall SERI mean on each of the ES\&H questions. 
4.9.4 Differences Between Staff Classifications on the Environment, Safety, and Health Questions

No statistically significant differences between staff classifications were obtained on any of the four ES\&H questions at SERI. Appendix B contains the mean values for each staff classification on each ES\&H question.

\subsubsection{Differences Between Supervisory Levels on the Environment, Safety, and Health Questions}

No statistically significant differences between supervisory levels were obtained on any of the ES\&H questions. Appendix C contains the mean values for each supervisory level on each of the ES\&H questions. 


\section{CONCLUSIONS}

The Organizational Culture Assessment (OCA) which took place at the Solar Energy Research Institute (SERI) on June 25 and 26, 1991, was the eighth to occur at a U.S. Department of Energy (DOE) facility, and the seventh to occur at a DOE facility prior to a Tiger Team Assessment. All 578 employees received notice of the OCA Administration. A total of 492 employees actually completed the survey, yielding a response rate of 85.1 percent.

The profile obtained on the scales which comprise the OCI (Human Synergistics, 1987), indicates the SERI organization places emphasis on those behaviors which can be considered "constructive" (i.e., Humanistic-Encouraging, Affiliative, Achievement, Self-Actualizing). The SERI organization also places emphasis, although to a lesser extent, on those behaviors which comprise the "Passive/Defensive" Cultural Style (i.e., Approval, Conventional, Dependent, Avoidance).

While the overall mean value obtained on the Communications - Interaction Scale was high, there was not a similarly high trust in communications, perceived accuracy in communications, or satisfaction with communications, as exemplified by the mean values obtained on those scales. Commitment to the SERI organization and cohesion to work groups were also high. However, profiles obtained at other DOE facilities which have taken the OCA survey typically have had mean values on the Cohesion Scale which were notably higher than those obtained on the Commitment Scale. At SERI, the mean values on these two scales were equivalent.

The recent reorganization which occurred at SERI may be one potential explanation for these findings. The reorganization involved employees being moved to other divisions/offices. Thus, in the time between the reorganization and the survey administration people may not yet have formed strong relationships with others in their immediate work groups, accounting for the equivalent Cohesion and Commitment Scale scores. This may also have had an effect on the communication processes within the organization, so that while employees of SERI have a high desire for interaction with others in the organization, they have not yet built trust within their working groups, and thus, the low Trust in Communication Scale score, the low perceived accuracy of communications, and the low overall satisfaction with communications. Another finding which may be related to the recent reorganization at SERI was the low perceived coordination of work among units at SERI.

The mean score on the Hazard Scale was low. This was not unexpected given the type of work which is conducted at SERI. Additionally, low mean scores were obtained on the potential for both on and offsite environmental consequences. Despite this, attention to safety appears high, as evidenced by the high mean value on the Safety Scale.

Few statistically significant differences between divisions/offices were obtained on the OCA. This finding could be indicative of an organization with a homogenous culture. No statistically significant differences were obtained on the OCI scales. Statistically significant differences obtained on the Hazard Scale and the Offsite and Onsite Questions were not unexpected and appear related to the work function of the divisions/offices. The Administrative Services Division and the Environment, Safety, and Health Section were the two divisions/offices most dissimilar on the OCA scales. These divisions/offices were statistically significantly different on every scale in which a significant difference was obtained.

Few statistically significant differences were obtained between staff classifications at SERI, another indication of the apparently homogeneous culture which exists. Statistically significant 
differences were obtained on the Conventional (C4) Scale, and the Hazard Scale. The differences obtained on the Hazard Scale appear related to work function.

No statistically significant differences were obtained between supervisory levels at SERI. This is a notable finding and is unlike results obtained at other DOE facilities. A closer examination of the results yielded some trends and patterns, however, they were not large enough to result in statistically significant differences. This may yet be another example of the homogeneous culture which appears to exist at SERI.

In summary, SERI, as represented by the sample of employees who completed the Organizational Culture Survey, is a homogeneous organization which places a high amount of emphasis on behaviors which might be considered "constructive." The differences obtained between divisions/offices and staff classifications are few. Most of the differences obtained, however, do appear consistent with work function. Of interest, is the fact that no statistically significant differences were found between supervisory levels, a finding which has not been obtained at other DOE facilities. 


\section{REFERENCES}

Cooke, R.A., and Burack, E.H., "Measuring Norms and Expectations with the OCI," in Organizational Culture Inventory, Level V Manual, Chicago: Human Synergistics, 1987, pp. 13-26.

Hays, W.L., Statistics, Fourth Edition, New York: Holt, Rinehart, and Winston, Inc., 1988.

Human Synergistics, Organizational Culture Inventory, Level V, Plymouth, MI, 1987.

Georgopolous, B.S., and Mann, F.C., The Community General Hospital, New York: Macmillan, 1962.

Kunin, J., "The construction of a new type of attitude measure," Personnel Psychology, $\underline{8}$, 1955, pp. 6578 .

Mowday, R., and Steers, R.M., The measurement of organizational commitment, Journal of Vocational Behavior, 14, 1979, pp. 224-247.

Price, J.L., and Muller, Handbook of Organizational Measurement, Lexington, MA: DC Heath and Company, 1972.

Roberts, K.M., and O'Reilly, C.A., "Measuring organizational communications," Journal of Applied Psychology, $\underline{59}$ (3), 1974, pp. 321-326 (copyright pending).

Seashore, S.E., Group Cohesiveness in the Industrial Work Group, Ann Arbor, MI: Survey Research Center, University of Michigan, MI, 1954. 


\author{
APPENDIX A: \\ SIGNIFICANT DIFFERENCES BETWEEN DIVISIONS/OFFICES \\ ON OCA SCALES
}




\begin{tabular}{|c|c|c|c|c|c|c|c|c|c|c|c|c|c|}
\hline Code & Division/Office & $\mathrm{Cl}$ & C2 & $\mathrm{C} 3$ & C4 & C5 & C6 & C7 & $\mathrm{C} 8$ & C9 & C10 & C11 & C12 \\
\hline \multirow[t]{2}{*}{1} & \multirow{2}{*}{$\begin{array}{l}\text { Administrative } \\
\text { Services Division }\end{array}$} & 3.19 & 3.45 & 2.91 & 3.11 & 3.15 & 2.44 & 2.45 & 2.64 & 2.33 & 3.02 & 3.46 & 3.08 \\
\hline & & & & & & & & & & & & & \\
\hline \multirow[t]{2}{*}{2} & \multirow{2}{*}{$\begin{array}{l}\text { Director's Office } \\
\text { (Legal, Tech. } \\
\text { Trans., DCO) }\end{array}$} & 3.38 & 3.48 & 2.86 & 3.10 & 3.14 & 2.29 & 2.23 & 2.50 & 2.32 & 2.93 & 3.66 & 3.2 .1 \\
\hline & & & & & & & & & & & & & \\
\hline \multirow[t]{2}{*}{3} & \multirow{2}{*}{$\begin{array}{l}\text { Energy \& Envi- } \\
\text { ronmental Analysis } \\
\text { Division }\end{array}$} & 3.52 & 3.48 & 2.49 & 2.50 & 2.68 & 1.83 & 2.15 & 2.09 & 2.18 & 2.73 & 3.85 & 3.28 \\
\hline & & & & & & & & & & & & & \\
\hline \multirow[t]{2}{*}{4} & \multirow{2}{*}{$\begin{array}{l}\text { Environment, Safe- } \\
\text { ty \& Health Section }\end{array}$} & 3.90 & 3.84 & 2.46 & 2.55 & 2.54 & 1.82 & 2.15 & 2.15 & 1.95 & 2.46 & 3.93 & 3.38 \\
\hline & & & & & & & & & & & & & \\
\hline \multirow[t]{2}{*}{5} & \multirow{2}{*}{$\begin{array}{l}\text { Fuels \& Chemicals } \\
\text { Research \& Engi- } \\
\text { neering Division }\end{array}$} & 3.48 & 3.54 & 2.72 & 2.89 & 3.00 & 2.20 & 2.42 & 2.35 & 2.34 & 2.96 & 3.75 & 3.37 \\
\hline & & & & & & & & & & & & & \\
\hline \multirow[t]{2}{*}{6} & \multirow{2}{*}{$\begin{array}{l}\text { Materials Science \& } \\
\text { Engineering Divi- } \\
\text { sion }\end{array}$} & 3.38 & 3.45 & 2.63 & 2.94 & 2.91 & 2.30 & 2.28 & 2.47 & 2.41 & 2.80 & 3.61 & 3.27 \\
\hline & & & & & & & & & & & & & \\
\hline \multirow[t]{2}{*}{7} & \multirow{2}{*}{$\begin{array}{l}\text { Mechanical \& } \\
\text { Industrial Tech- } \\
\text { nology Division }\end{array}$} & 3.43 & 3.43 & 2.90 & 3.00 & 3.08 & 2.24 & 2.31 & 2.52 & 2.49 & 2.86 & 3.64 & 3.23 \\
\hline & & & & & & & & & & & & & \\
\hline \multirow[t]{2}{*}{8} & \multirow{2}{*}{$\begin{array}{l}\text { Technical Services } \\
\text { Division }\end{array}$} & 3.38 & 3.57 & 2.67 & 2.88 & 3.08 & 2.14 & 2.31 & 2.29 & 2.22 & 2.78 & 3.60 & 3.19 \\
\hline & & & & & & & & & & & & & \\
\hline
\end{tabular}

First line of each box $=$ mean for division on that scale.

Second and third line of each box = those divisions (coded by number) that the division is significantly different from. 


\begin{tabular}{|c|c|c|c|c|c|c|c|c|c|c|c|}
\hline Code & Division/OMice & COT & COH & HAZ & SAF & COD & JOB & CMT & CMA & CMI & CMS \\
\hline \multirow[t]{2}{*}{1} & \multirow{2}{*}{$\begin{array}{l}\text { Administrative } \\
\text { Services Division }\end{array}$} & 4.45 & 4.89 & 2.53 & 5.31 & 3.62 & 4.45 & 4.29 & 4.72 & 5.44 & 4.28 \\
\hline & & 4 & & $4,5,6$ & & & 4 & & & & \\
\hline \multirow[t]{2}{*}{2} & \multirow{2}{*}{$\begin{array}{l}\text { Director's Office } \\
\text { (Legal, Tech. } \\
\text { Transfer, DCO) }\end{array}$} & 5.24 & 4.94 & 2.09 & 5.66 & 4.06 & 5.25 & 4.88 & 5.12 & 5.75 & 4.80 \\
\hline & & & & $4,5,6,8,7$ & & & & & & & \\
\hline \multirow[t]{2}{*}{3} & \multirow{2}{*}{$\begin{array}{l}\text { Energy \& Envi- } \\
\text { ronmental Analy- } \\
\text { sis Division }\end{array}$} & 5.30 & 5.30 & 2.34 & 5.49 & 4.06 & 5.15 & 4.88 & 5.13 & 5.87 & 5.05 \\
\hline & & & & $4,5,6,8,7$ & & & & & & & \\
\hline \multirow[t]{2}{*}{4} & \multirow{2}{*}{$\begin{array}{l}\text { Environment, } \\
\text { Safety \& Health } \\
\text { Section }\end{array}$} & 5.87 & 5.80 & 4.38 & 5.92 & 4.80 & 5.60 & 5.45 & 5.48 & 5.50 & 5.30 \\
\hline & & 1 & & $1,3,2$ & & & 1 & & & & \\
\hline \multirow[t]{2}{*}{5} & \multirow{2}{*}{$\begin{array}{l}\text { Fuels \& Chemi- } \\
\text { cals Research \& } \\
\text { Engineering Divi- } \\
\text { sion }\end{array}$} & 5.28 & 5.57 & 4.03 & 5.64 & 4.15 & 5.40 & 4.63 & 4.97 & 5.77 & 4.73 \\
\hline & & & & $1,3,2$ & & & & & & & \\
\hline \multirow[t]{2}{*}{6} & \multirow{2}{*}{$\begin{array}{l}\text { Materials Science } \\
\text { \& Engineering } \\
\text { Division }\end{array}$} & 5.26 & 5.17 & 3.73 & 5.57 & 4.03 & 5.23 & 4.64 & 5.08 & 5.73 & 4.85 \\
\hline & & & & $1,3,2$ & & & & & & & \\
\hline \multirow[t]{2}{*}{7} & \multirow{2}{*}{$\begin{array}{l}\text { Mechanical \& } \\
\text { Industrial Tech- } \\
\text { nology Division }\end{array}$} & 4.99 & 4.88 & 3.44 & 5.54 & 4.01 & 5.06 & 4.56 & 4.76 & 5.80 & 4.71 \\
\hline & & & & 3,2 & & & & & & & \\
\hline \multirow[t]{2}{*}{8} & \multirow{2}{*}{$\begin{array}{l}\text { Technical Services } \\
\text { Division }\end{array}$} & 5.32 & 5.17 & 3.52 & 5.54 & 4.01 & 5.48 & 4.85 & 4.83 & 5.36 & 4.92 \\
\hline & & & & 3,2 & & & & & & & \\
\hline
\end{tabular}

First line of each box $=$ mean for division on that scale.

Second and third line of each box $=$ those divisions (coded by number) that the division is significantly different from. 


\begin{tabular}{|c|c|c|c|c|c|}
\hline Code & Division/Office & OFF & ONS & MGE & EMA \\
\hline \multirow[t]{2}{*}{1} & \multirow{2}{*}{$\begin{array}{l}\text { Administrative } \\
\text { Services Division }\end{array}$} & 1.92 & 2.03 & 5.59 & 5.37 \\
\hline & & 4 & 4,5 & & \\
\hline \multirow[t]{2}{*}{2} & \multirow{2}{*}{$\begin{array}{l}\text { Director's Office } \\
\text { (Legal, Tech. } \\
\text { Trans., DCO) } \\
\end{array}$} & 1.48 & 1.71 & 5.32 & 5.13 \\
\hline & & 4,5 & 4,5 & & \\
\hline \multirow[t]{2}{*}{3} & \multirow{2}{*}{$\begin{array}{l}\text { Energy \& Envi- } \\
\text { ronmental Analy- } \\
\text { sis Division }\end{array}$} & 2.15 & 1.90 & 5.65 & 5.90 \\
\hline & & 4 & 4,5 & & \\
\hline \multirow[t]{2}{*}{4} & \multirow{2}{*}{$\begin{array}{l}\text { Environment, } \\
\text { Safety \& Health } \\
\text { Section }\end{array}$} & 4.30 & 4.60 & 6.40 & 6.30 \\
\hline & & $1,2,3,5,6,7,8$ & $1,2,3,6,7,8$ & & \\
\hline \multirow[t]{2}{*}{5} & \multirow{2}{*}{$\begin{array}{l}\text { Fuels \& Chemi- } \\
\text { cals Research \& } \\
\text { Engineering Divi- } \\
\text { sion }\end{array}$} & 2.75 & 3.35 & 5.42 & 5.62 \\
\hline & & 4,2 & $1,3,2$ & & \\
\hline \multirow[t]{2}{*}{6} & \multirow{2}{*}{$\begin{array}{l}\text { Materials Science } \\
\text { \& Engineering } \\
\text { Division }\end{array}$} & 2.15 & 2.58 & 5.54 & 5.78 \\
\hline & & 4 & 4 & & \\
\hline \multirow[t]{2}{*}{7} & \multirow{2}{*}{$\begin{array}{l}\text { Mechanical \& } \\
\text { Industrial Tech- } \\
\text { nology Division }\end{array}$} & 2.13 & 2.19 & 5.62 & 5.89 \\
\hline & & 4 & 4 & & \\
\hline \multirow[t]{2}{*}{8} & \multirow{2}{*}{$\begin{array}{l}\text { Technical Services } \\
\text { Division }\end{array}$} & 2.54 & 2.68 & 5.36 & 5.30 \\
\hline & & 4 & 4 & & \\
\hline
\end{tabular}

First line of each box $=$ mean for division on that scale.

Second and third line of each box = those divisions (coded by number) that the division is significantly different from. 
APPENDIX B:

SIGNIFICANT DIFFERENCES BETWEEN STAFF CLASSIFICATIONS ON OCA SCALES 


\begin{tabular}{|c|c|c|c|c|c|c|c|c|c|c|c|c|c|}
\hline Code & Staff Classification & C1 & C2 & $\mathrm{C3}$ & $\mathrm{CA}$ & C5 & C6 & C7 & C8 & C9 & $\mathrm{C10}$ & C11 & $\mathrm{C} 12$ \\
\hline \multirow[t]{2}{*}{1} & \multirow[t]{2}{*}{ Management } & 3.51 & 3.53 & 2.70 & 2.85 & 2.89 & 2.32 & 2.46 & 2.57 & 2.48 & 2.79 & 3.64 & 3.22 \\
\hline & & & & & 5 & & & & & & & & \\
\hline \multirow[t]{2}{*}{2} & \multirow[t]{2}{*}{ Administration } & 3.27 & 3.47 & 2.86 & 3.08 & 3.11 & 2.30 & 2.30 & 2.51 & 2.29 & 2.93 & 3.55 & 3.13 \\
\hline & & & & & 6 & & & & & & & & \\
\hline \multirow[t]{2}{*}{3} & \multirow{2}{*}{$\begin{array}{l}\text { Research (Scientist } \\
\text { or Engineer) }\end{array}$} & 3.44 & 3.48 & 2.69 & 2.86 & 2.94 & 2.17 & 2.32 & 2.43 & 2.43 & 2.84 & 3.72 & 3.31 \\
\hline & & & & & & & & & & & & & \\
\hline \multirow[t]{2}{*}{4} & \multirow[t]{2}{*}{ Non-Exempt } & 3.39 & 3.64 & 2.91 & 3.09 & 3.19 & 2.32 & 2.32 & 2.46 & 2.28 & 2.99 & 3.64 & 3.22 \\
\hline & & & & & 6 & & & & & & & & \\
\hline \multirow[t]{2}{*}{5} & \multirow[t]{2}{*}{ Technician } & 3.12 & 3.32 & 2.94 & 3.29 & 3.30 & 2.45 & 2.30 & 2.49 & 2.28 & 2.96 & 3.34 & 3.02 \\
\hline & & & & & 1,6 & & & & & & & & \\
\hline \multirow[t]{2}{*}{6} & \multirow{2}{*}{$\begin{array}{l}\text { Other (temporaries, } \\
\text { post-docs, visitors, } \\
\text { students) }\end{array}$} & 3.56 & 3.57 & 2.44 & 2.65 & 2.81 & 2.06 & 2.28 & 2.15 & 2.12 & 2.78 & 3.72 & 3.44 \\
\hline & & & & & $5,2,4$ & & & & & & & & \\
\hline
\end{tabular}

First line of each box $=$ mean for staff classification on that scale.

Second and third line of each box = those staff classifications (coded by number) that the staff classification is significantly different from. 


\begin{tabular}{|c|c|c|c|c|c|c|c|c|c|c|c|}
\hline Code & Staff Classification & COT & COH & HAZ & SAF & COD & JOB & CMT & CMA & CMI & CMS \\
\hline \multirow[t]{2}{*}{1} & \multirow[t]{2}{*}{ Management } & 5.05 & 5.21 & 3.16 & 5.50 & 3.87 & 4.84 & 4.64 & 4.91 & 5.66 & 4.61 \\
\hline & & & & 5 & & & & & & & \\
\hline \multirow[t]{2}{*}{2} & \multirow[t]{2}{*}{ Administration } & 4.78 & 4.98 & 2.52 & 5.53 & 3.78 & 4.90 & 4.58 & 4.94 & 5.54 & 4.49 \\
\hline & & & & $5,3,6$ & & & & & & & \\
\hline \multirow[t]{2}{*}{3} & \multirow{2}{*}{$\begin{array}{l}\text { Research (crientist } \\
\text { or Engineer) }\end{array}$} & 5.21 & 5.41 & 3.63 & 5.54 & 4.09 & 5.37 & 4.66 & 5.10 & 5.79 & 4.91 \\
\hline & & & & 4,2 & & & & & & & \\
\hline \multirow[t]{2}{*}{4} & \multirow[t]{2}{*}{ Non-exempt } & 5.38 & 5.00 & 2.79 & 5.61 & 4.06 & 4.98 & 4.59 & 4.88 & 5.62 & 4.56 \\
\hline & & & & $5,3,6$ & & & & & & & \\
\hline \multirow[t]{2}{*}{5} & \multirow[t]{2}{*}{ Technician } & 5.07 & 4.76 & 4.35 & 5.52 & 3.72 & 5.26 & 4.49 & 4.57 & 5.37 & 4.38 \\
\hline & & & & $1,4,2$ & & & & & & & \\
\hline \multirow[t]{2}{*}{6} & \multirow{2}{*}{$\begin{array}{l}\text { Other (temporaries, } \\
\text { post-docs, visitors, } \\
\text { students) }\end{array}$} & 5.42 & 5.10 & 3.62 & 5.62 & 4.46 & 5.47 & 4.95 & 4.88 & 5.59 & 5.33 \\
\hline & & & & 4,2 & & & & & & & \\
\hline
\end{tabular}

First line of each box = mean for staff classification on that scale.

Second and third line of each box = those staff classifications (coded by number) that the staff classification is significantly different from. 


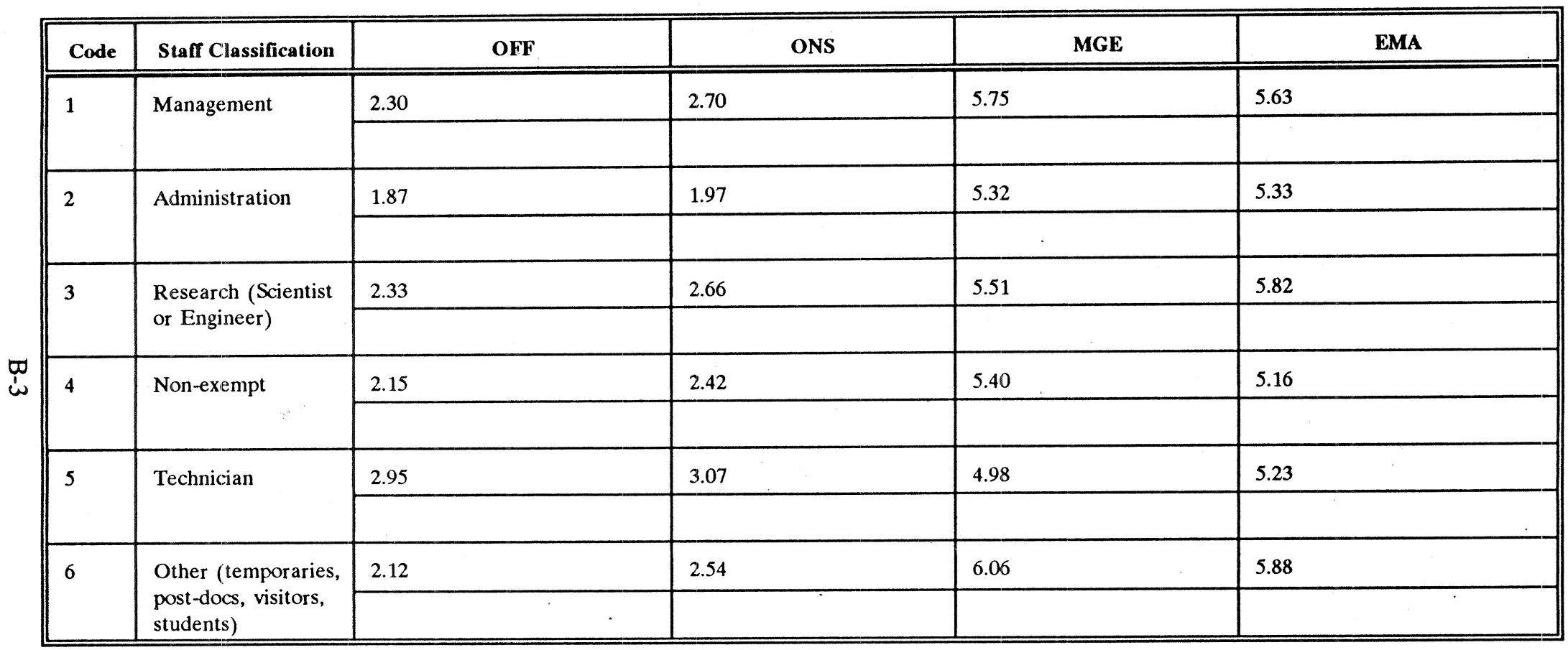

First line of each box $=$ mean for staff classification on that scale.

Second and third line of each box $=$ those staff classifications (coded by number) that the staff classification is significantly different from. 
APPENDIX C:

SIGNIFICANT DIFFERENCES BETWEEN SUPERVISORY LEVELS ON OCA SCALES 


\begin{tabular}{|c|c|c|c|c|c|c|c|c|c|c|c|c|c|}
\hline Code & Level & C1 & C2 & C3 & C4 & C5 & C6 & C7 & C8 & C9 & C10 & C11 & $\mathrm{C12}$ \\
\hline 1 & Supervisor & 3.55 & 3.52 & 2.67 & 2.85 & 2.94 & 2.20 & 2.34 & 2.49 & 2.43 & 2.80 & 3.68 & 3.23 \\
\hline 2 & Non-supervisor & 3.32 & 3.48 & 2.79 & 3.00 & 3.06 & 2.28 & 2.32 & 2.43 & 2.32 & 2.90 & 3.60 & 3.23 \\
\hline
\end{tabular}

\begin{tabular}{|c|c|c|c|c|c|c|c|c|c|c|c|}
\hline Code & Level & COT & COH & HAZ & SAF & COD & JOB & CMT & CMA & CMI & CIMS \\
\hline 1 & Supervisor & 5.15 & 5.38 & 3.46 & 5.59 & 3.90 & 5.09 & 4.66 & 5.09 & 5.79 & 4.83 \\
\hline 2 & Non-supervisor & 5.09 & 5.05 & 3.23 & 5.53 & 4.03 & 5.16 & 4.62 & 4.89 & 5.57 & 4.69 \\
\hline
\end{tabular}

\begin{tabular}{||l|l|l|l|l|l||}
\hline \hline Code & Level & \multicolumn{1}{|c|}{ OFF } & \multicolumn{1}{c|}{ ONS } & \multicolumn{1}{c|}{ MGE } & EMA \\
\hline \hline \multirow{2}{*}{1} & \multirow{2}{*}{ Supervisor } & 2.37 & 2.68 & 5.61 & 5.81 \\
\cline { 3 - 7 } & & & & 5.46 & 5.48 \\
\hline \multirow{2}{*}{2} & \multirow{2}{*}{ Non-supervisor } & 2.21 & 2.47 & & \\
\cline { 3 - 7 } & & & & \\
\hline
\end{tabular}

First line of each box $=$ mean for level on that scale.

Second and third line of each box $=$ those levels (coded by number) that the level is significantly different from. 
APPENDIX D:

COMPARISON OF SERI DVISIONS/OFFICES TO OVERALL SERI MEAN VALUES ON OCI SCALES 


\section{COMPARISON OF SERI OVERALL MEANS TO THE ADMINISTRATIVE SERVICES DIVISION MEANS ON THE OCI SCALES}

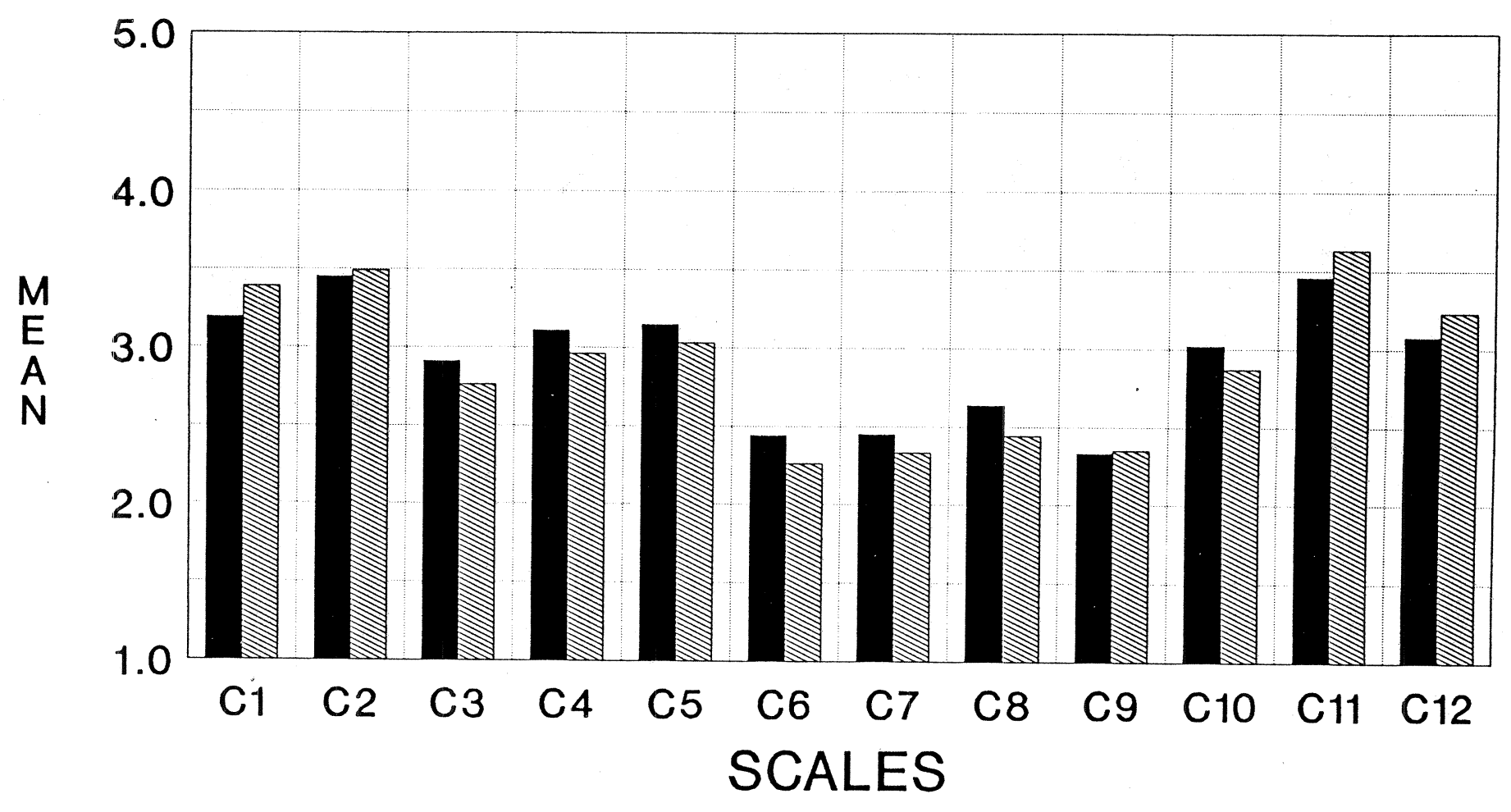

SERI ADM 



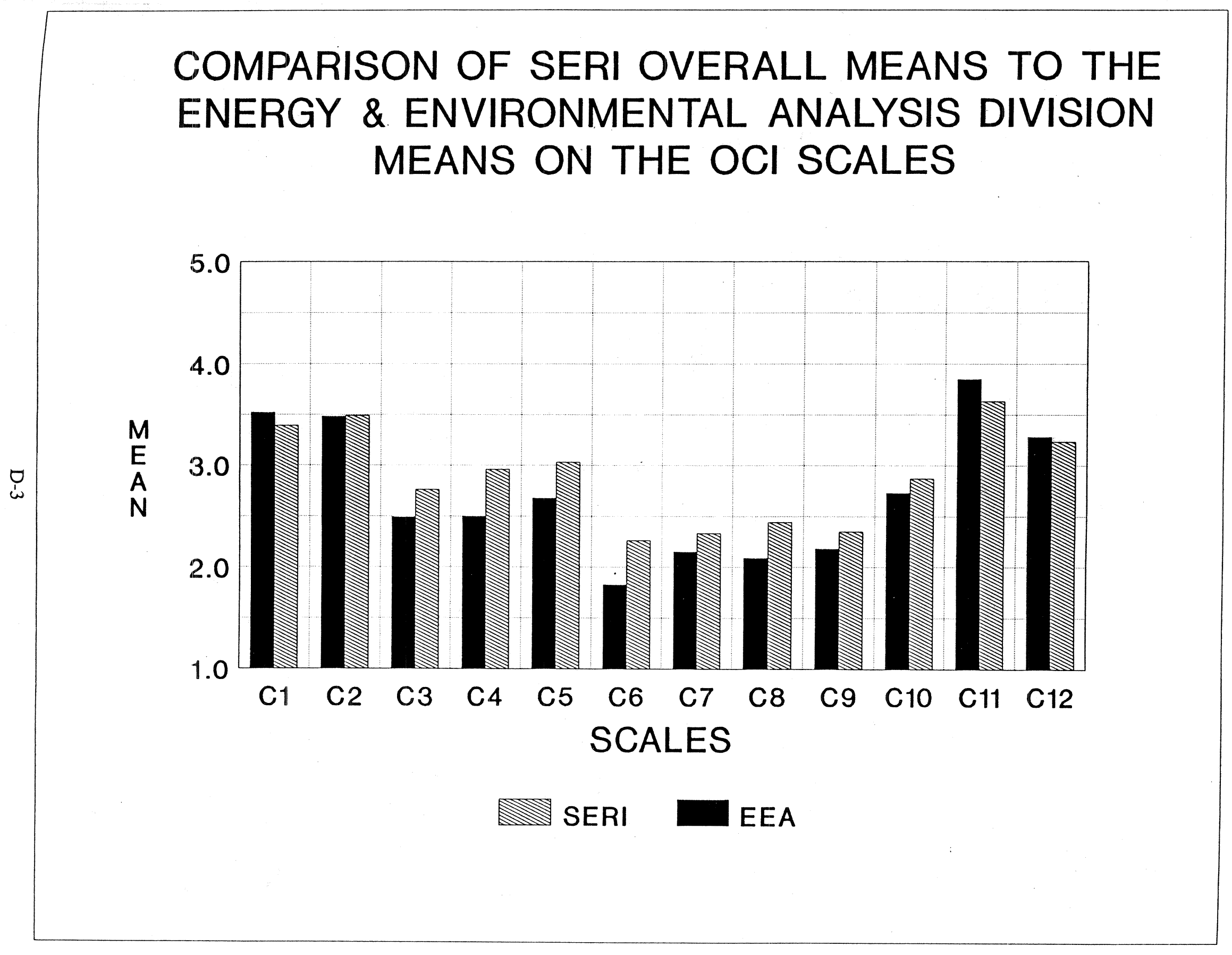




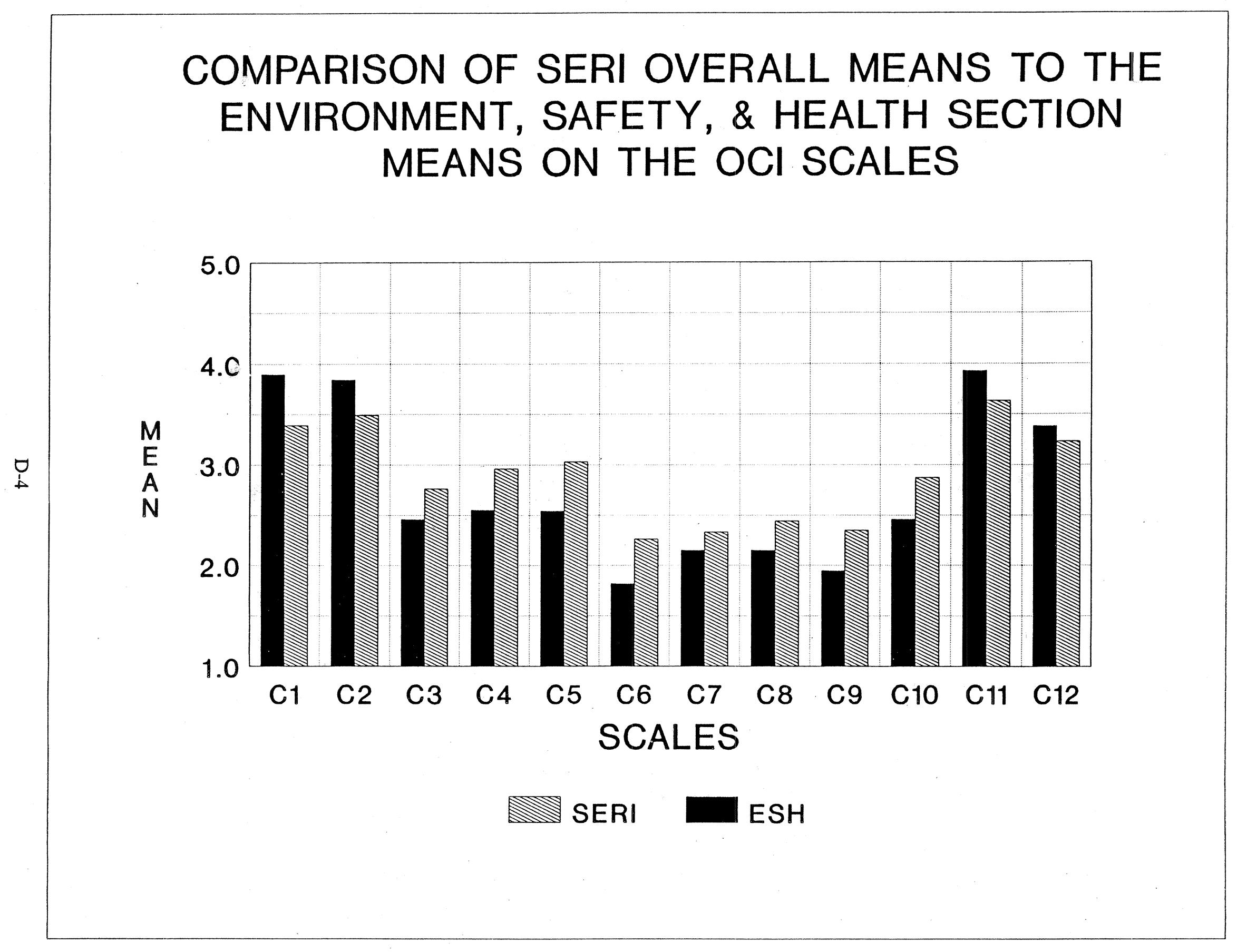




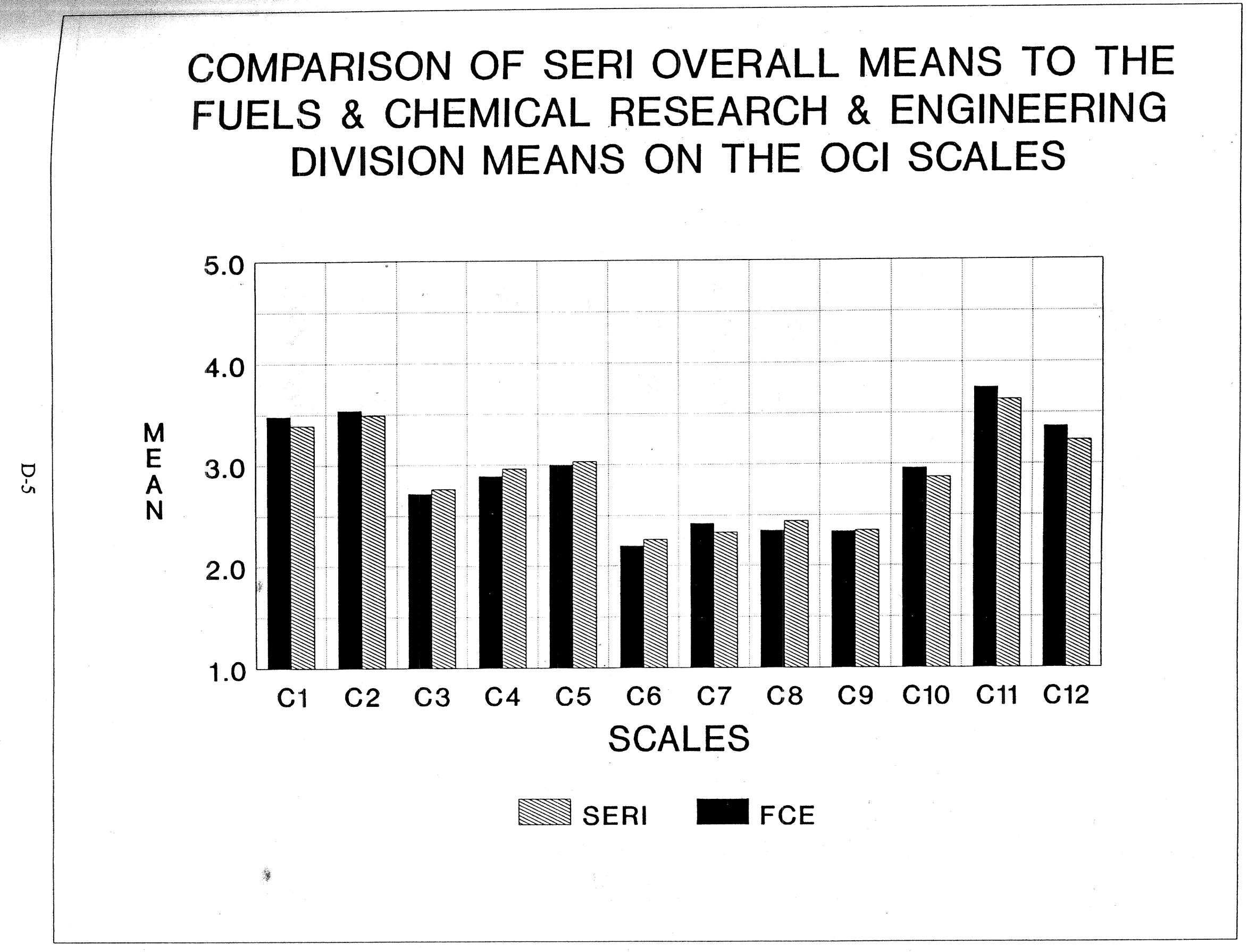


COMPARISON OF SERI OVERALL MEANS TO THE MATERIALS SCIENCE \& ENGINEERING DIVISION MEANS ON THE OCI SCALES

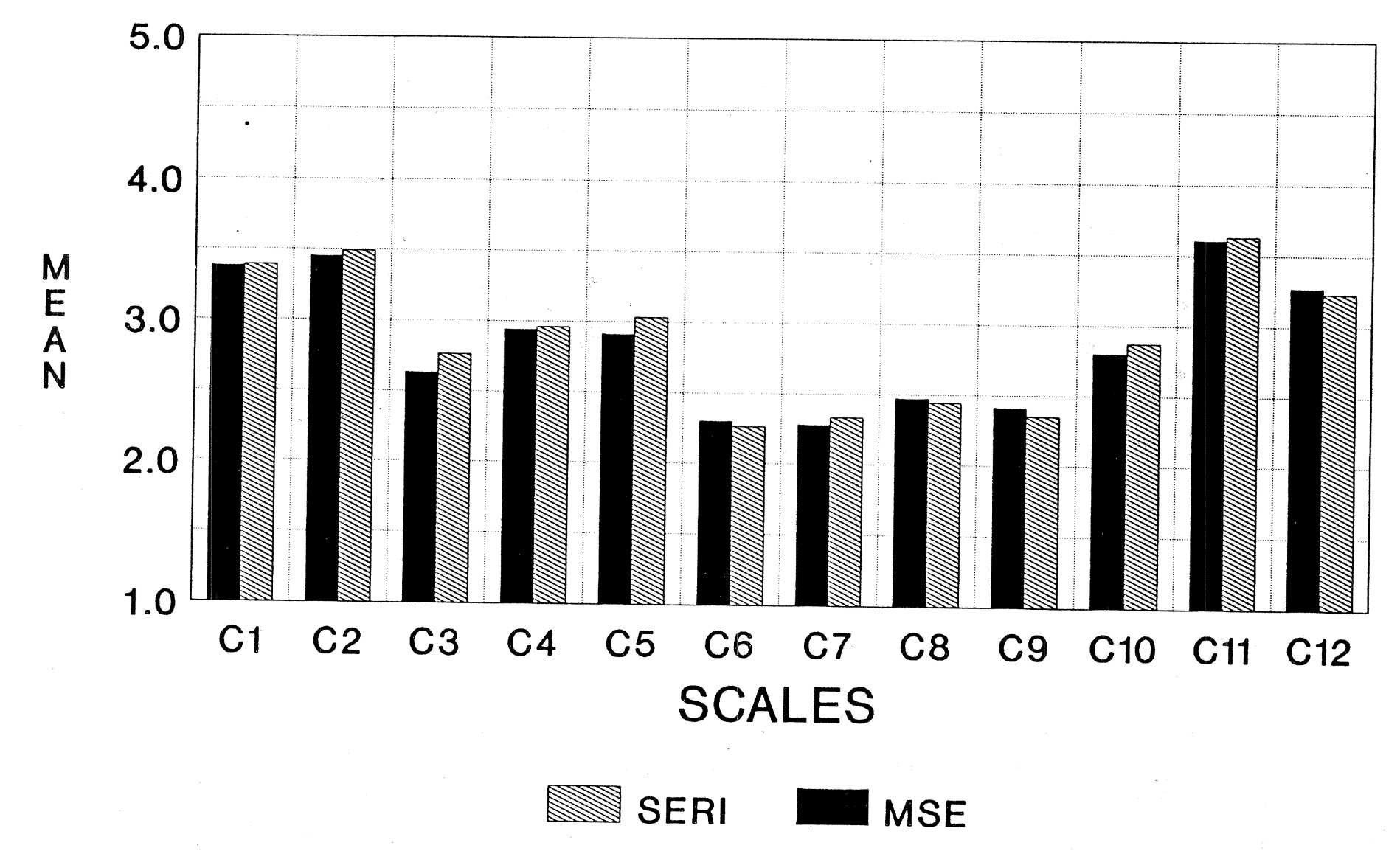




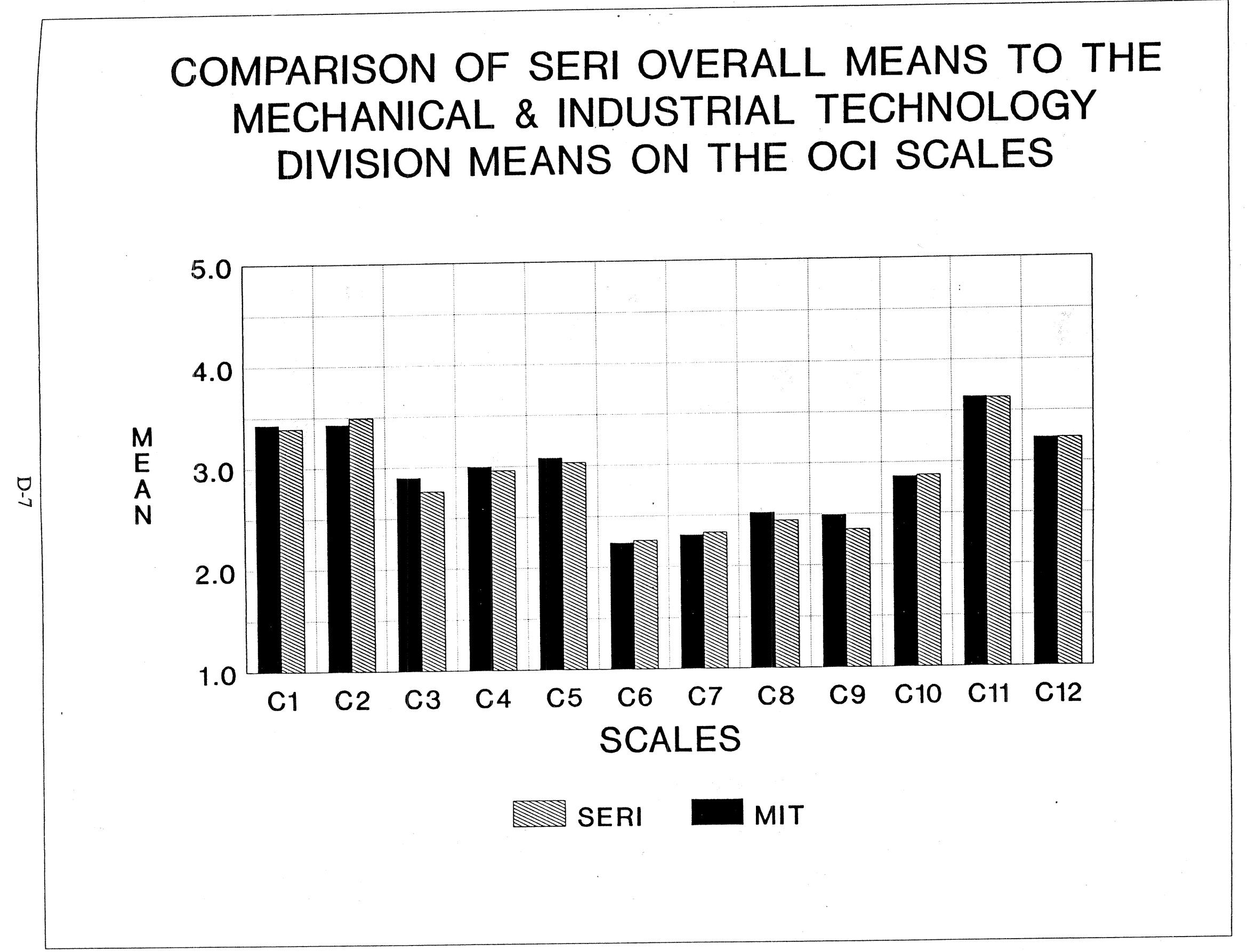




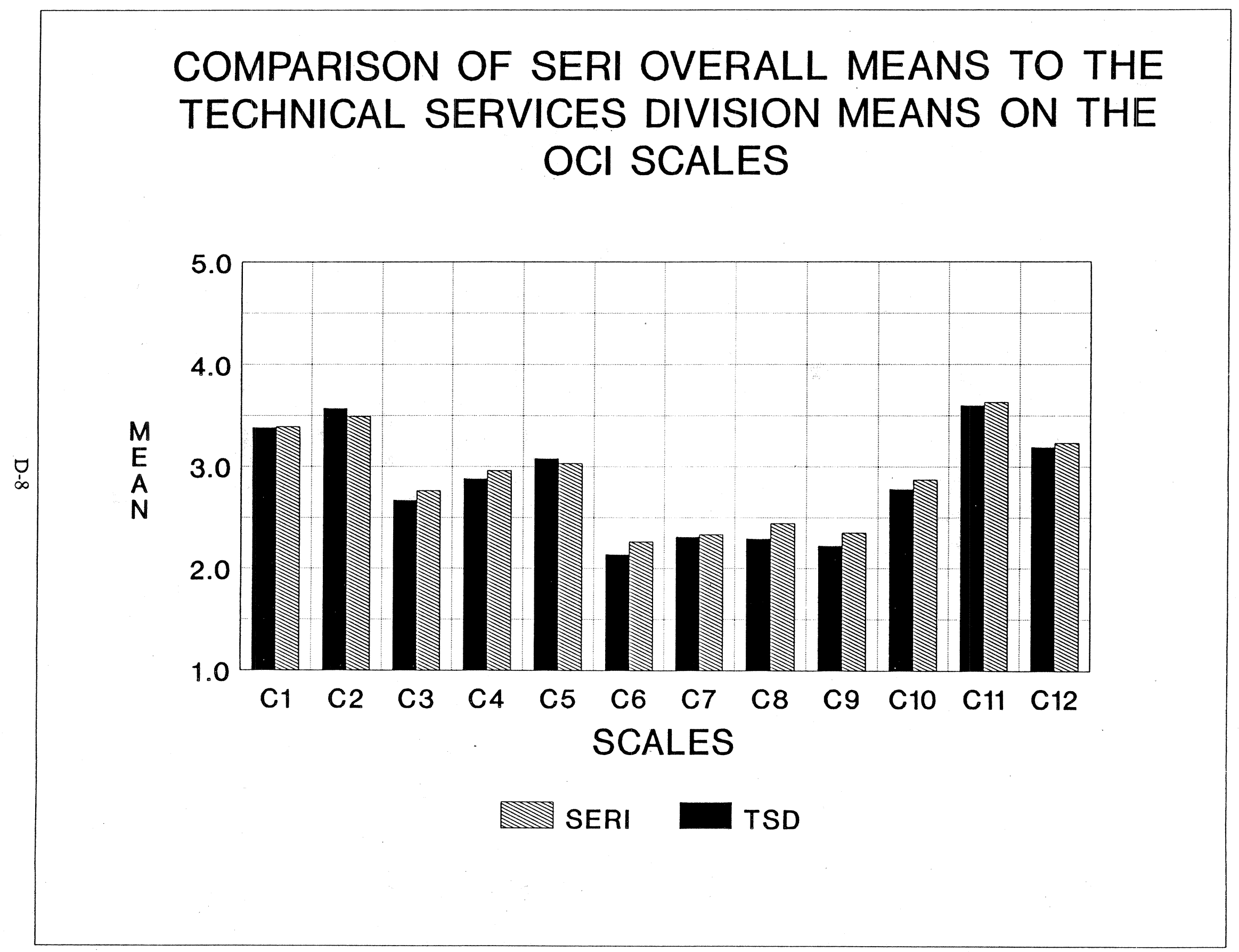




\section{APPENDIX E:}

COMPARISON OF SERI DIVISIONS/OFFICES TO OVERALL

SERI MEAN VALUES ON COMMUNICATION SCALES 


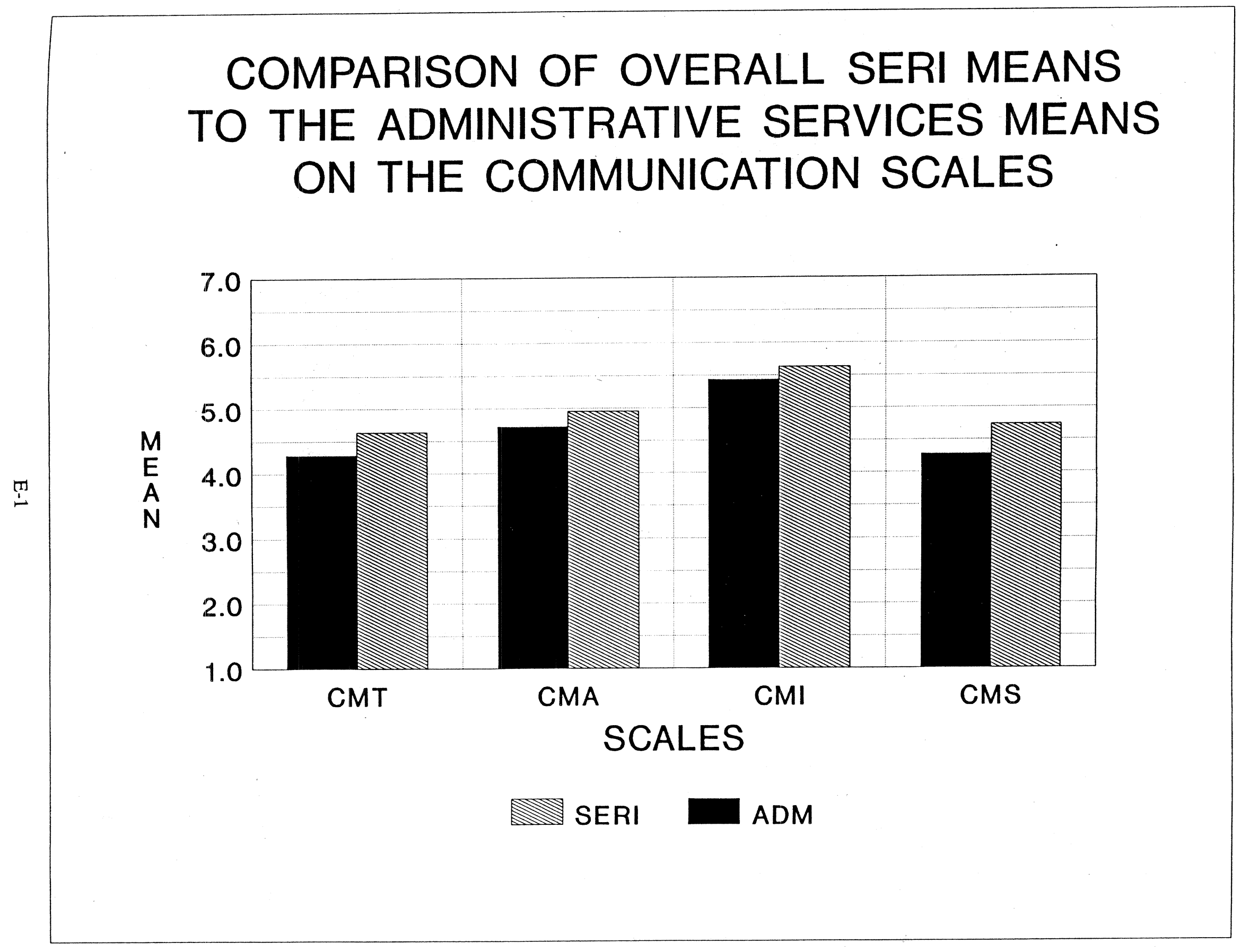




\section{COMPARISON OF SERI OVERALL MEANS TO}

THE DIRECTOR'S OFFICE MEANS ON THE COMMUNICATION SCALES

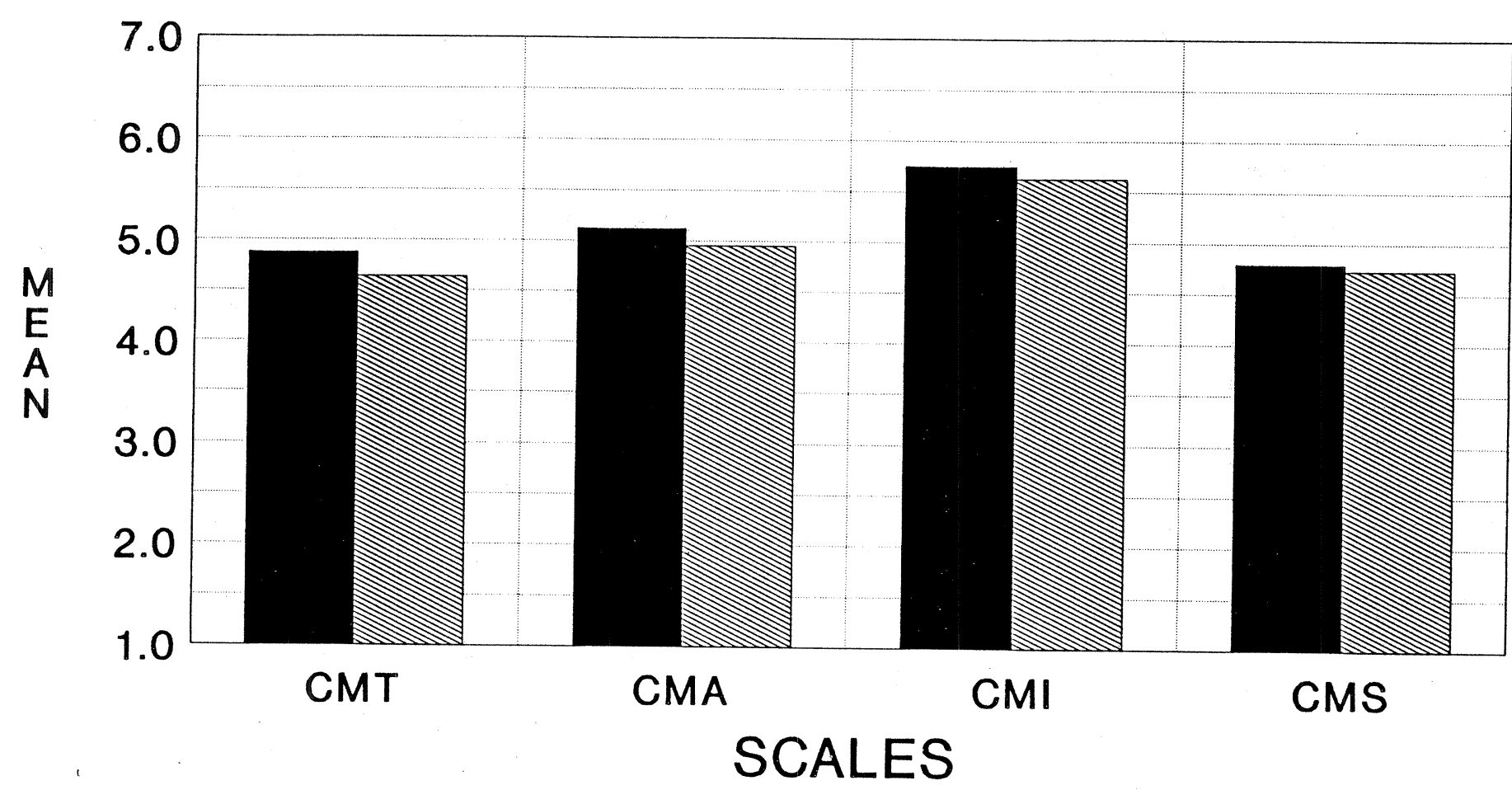

SERI DIR 


\section{COMPARISON OF SERI MEANS TO THE ENERGY \& ENVIRONMENTAL ANALYSIS DIVISION MEANS ON THE COMMUNICATION SCALES}

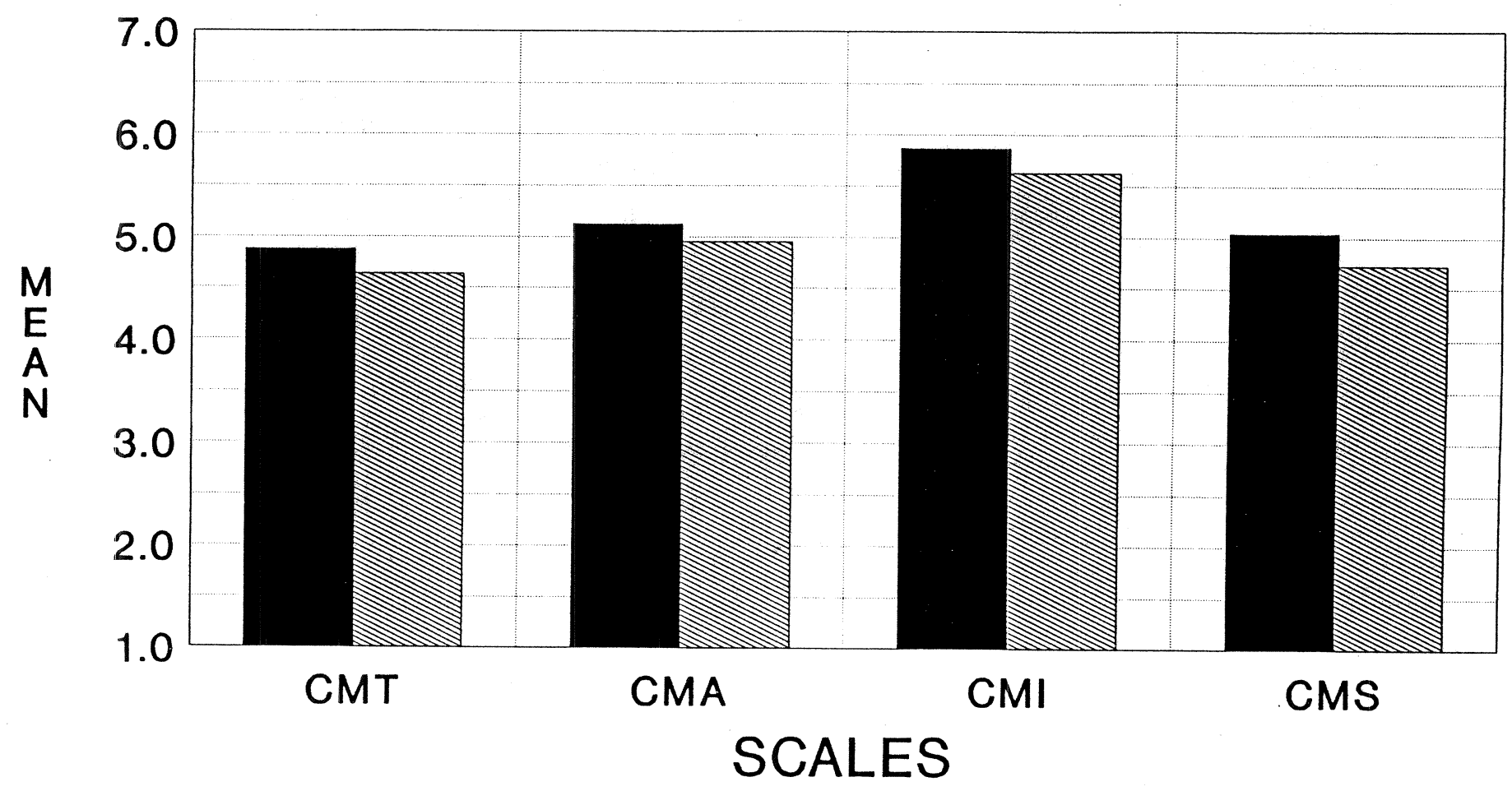

SERI EEA 
COMPARISON OF SERI OVERALL MEANS TO THE ENVIRONMENT, SAFETY \& HEALTH SECTION MEANS ON THE COMMUNICATION SCALES

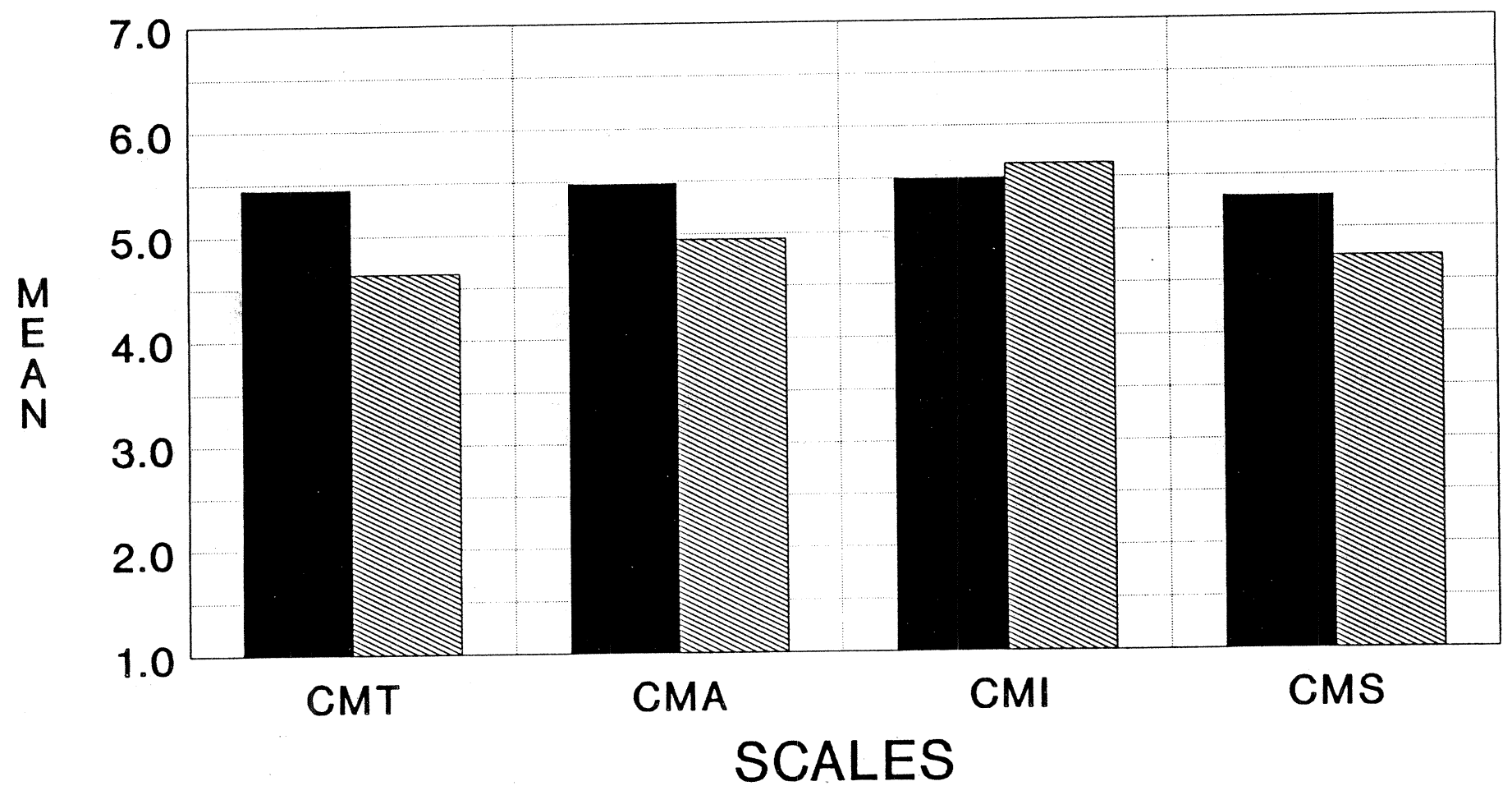

SERI $\square$ ESH 


\section{COMPARISON OF SERI OVERALL MEANS TO THE FCE* DIVISION MEANS ON THE COMMUNICATION SCALES}

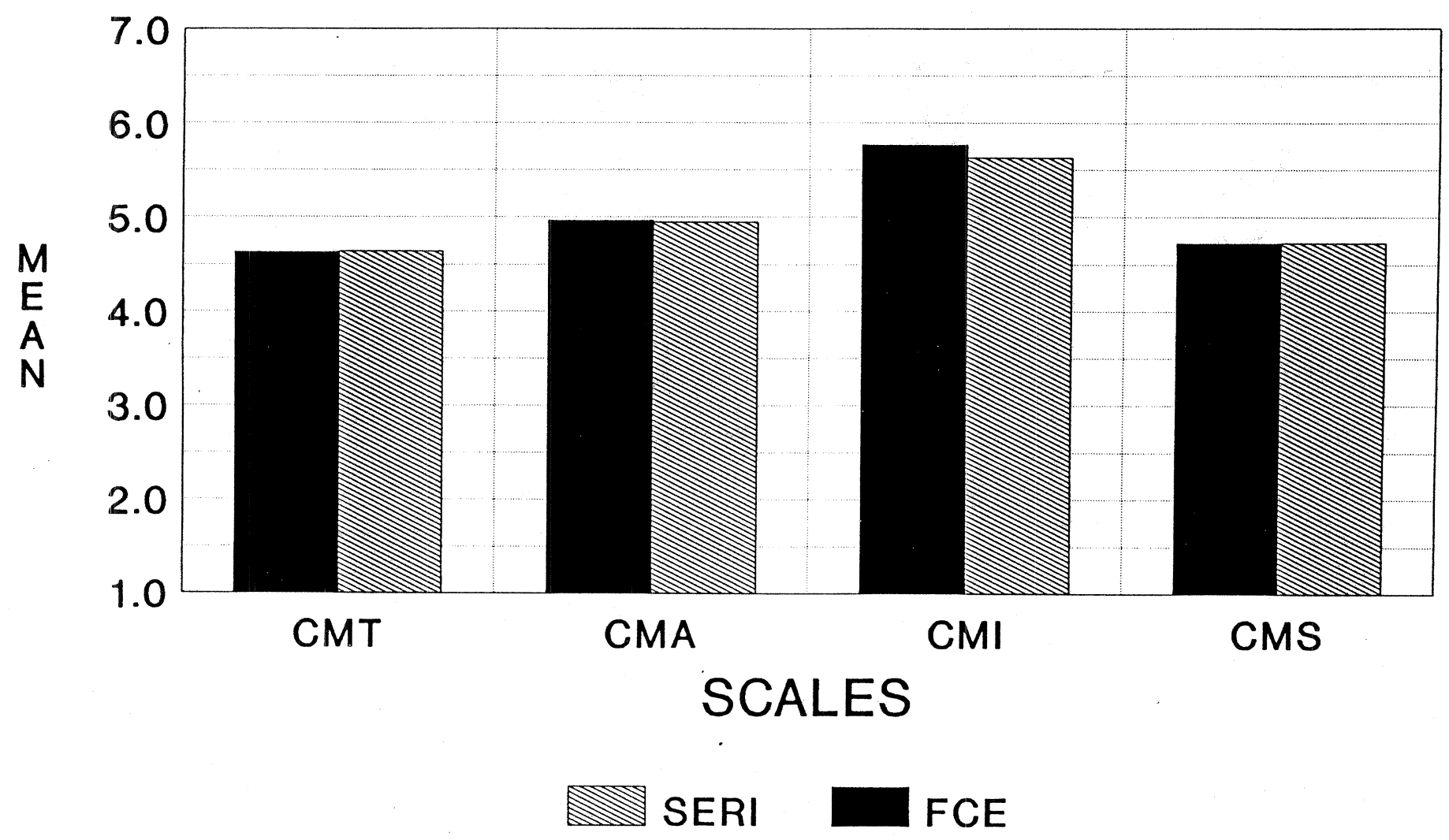

*FCE = Fuels and Chemicals Research \& Engineering Division Means 
COMPARISON OF SERI OVERALL MEANS TO THE MATERIALS SCIENCE \& ENGINEERING DIVISION MEANS ON THE COMMUNICATION SCALES
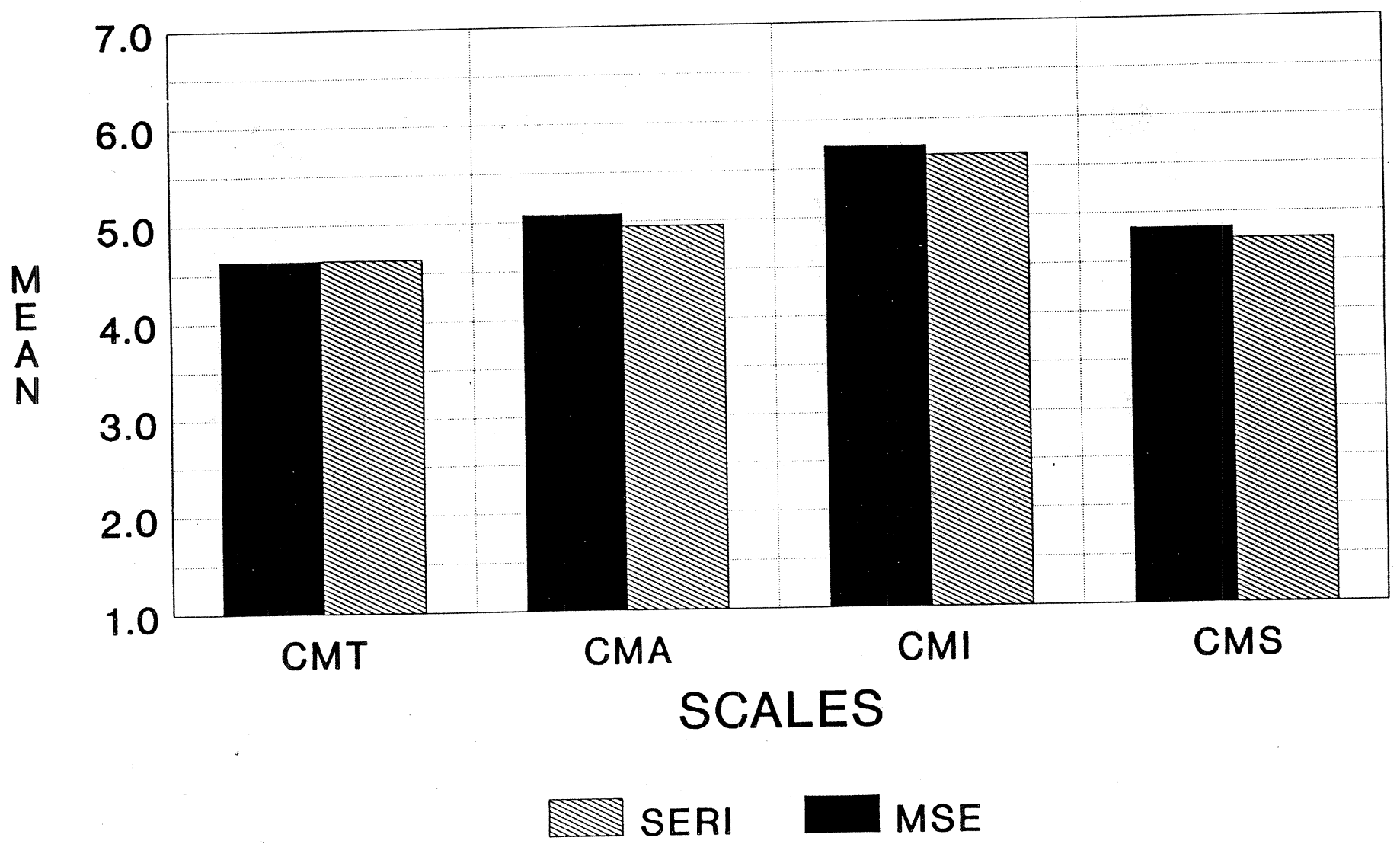
COMPARISON OF SERI OVERALL MEANS TO THE MECHANICAL \& INDUSTRIAL TECHNOLOGY DIVISION MEANS ON THE COMMUNICATION SCALES

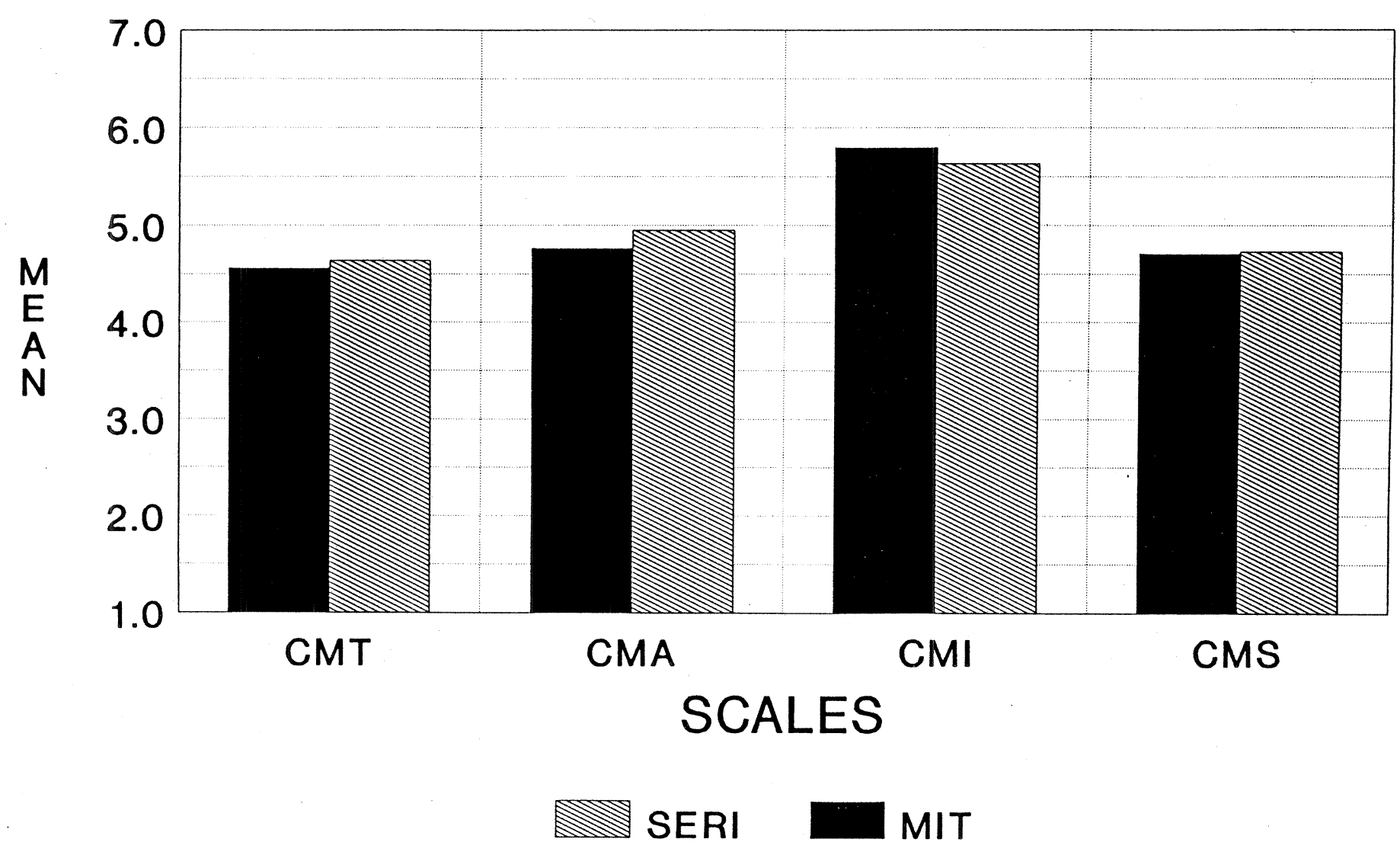


APPENDIX F:

COMPARISON OF SERI DIVISIONS/OFFICES TO OVERALL SERI MEAN VALUES ON ADDITIONAL SCALES 


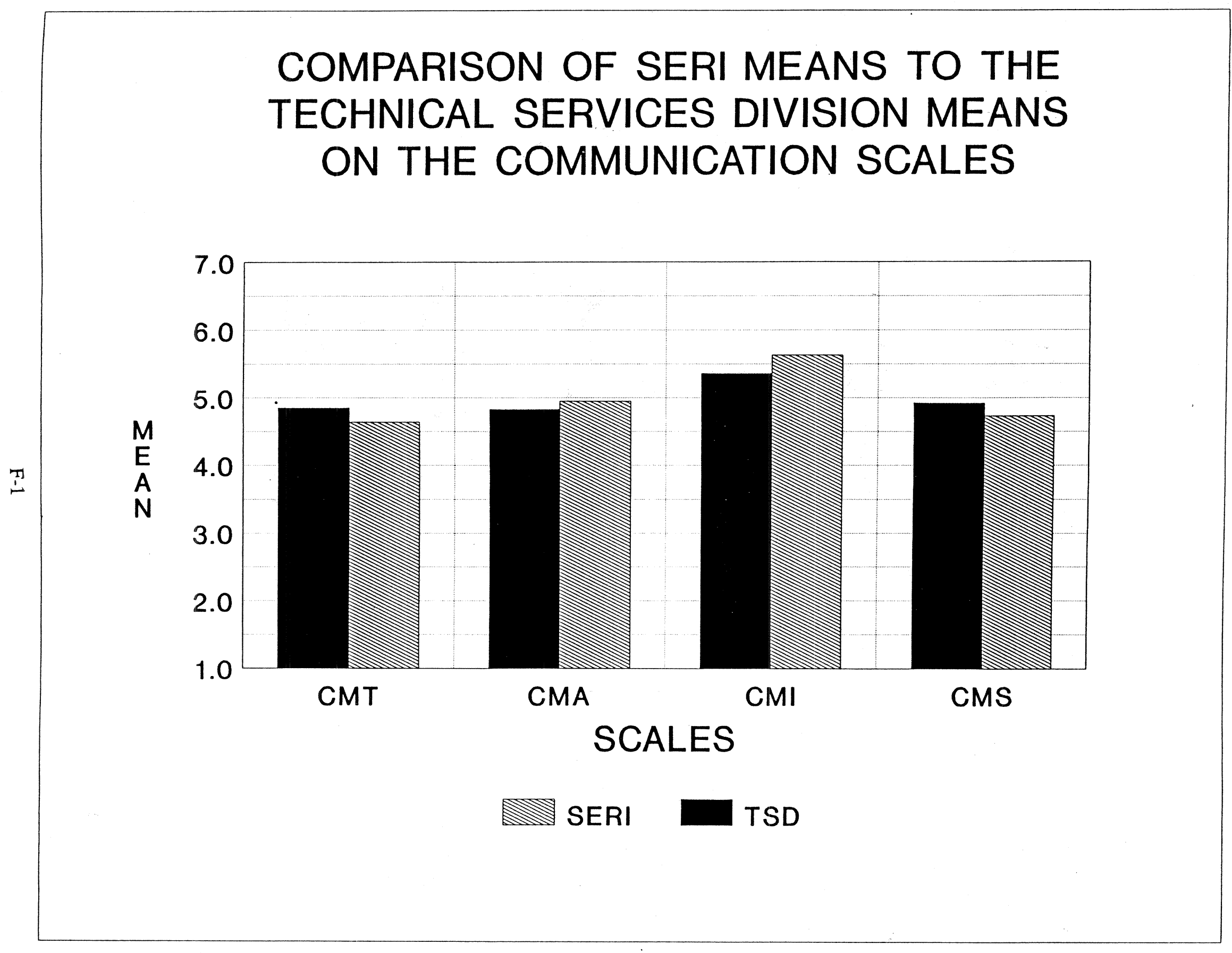




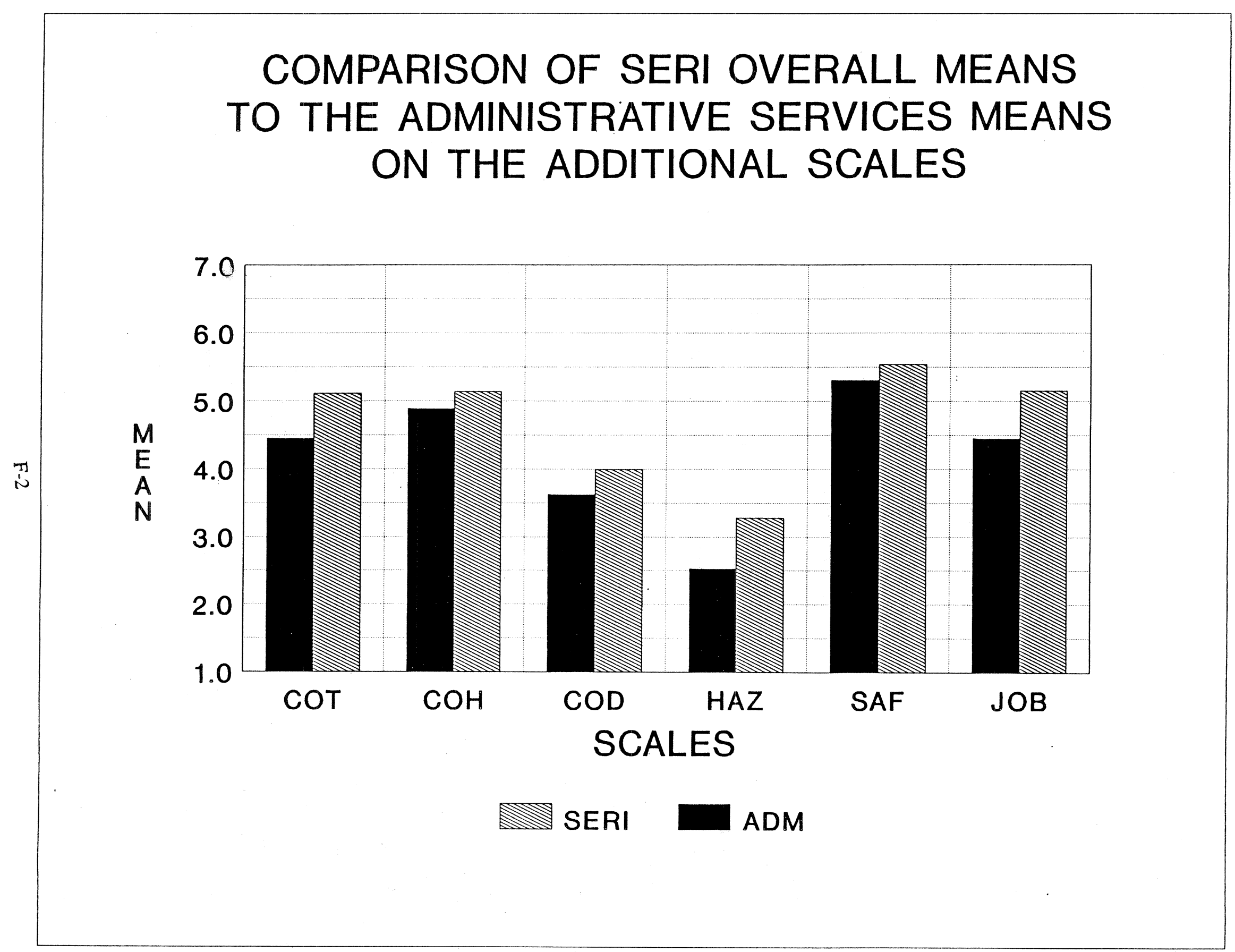




\section{COMPARISON OF SERI OVERALL MEANS TO THE DIRECTOR'S OFFICE MEANS ON THE ADDITIONAL SCALES}
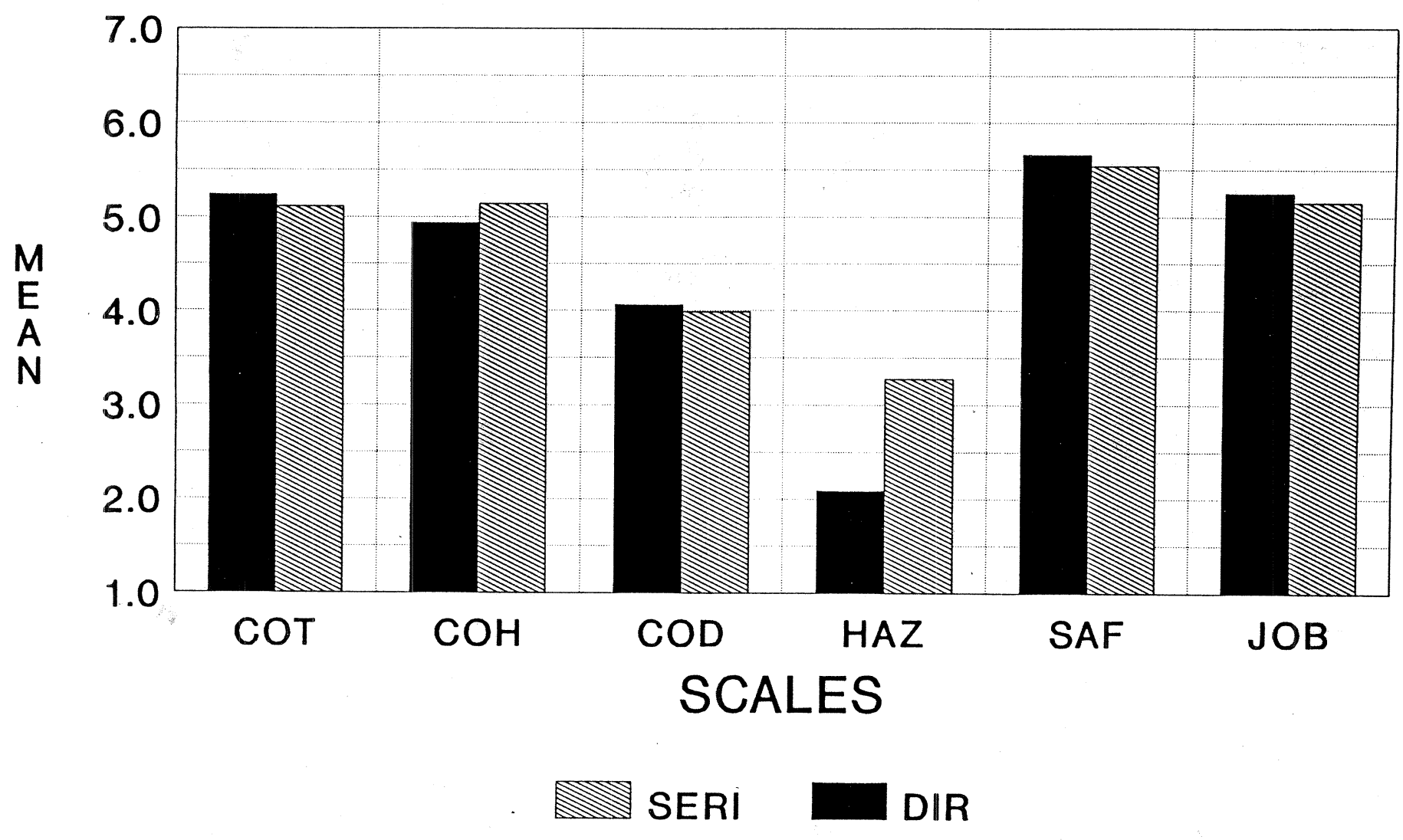


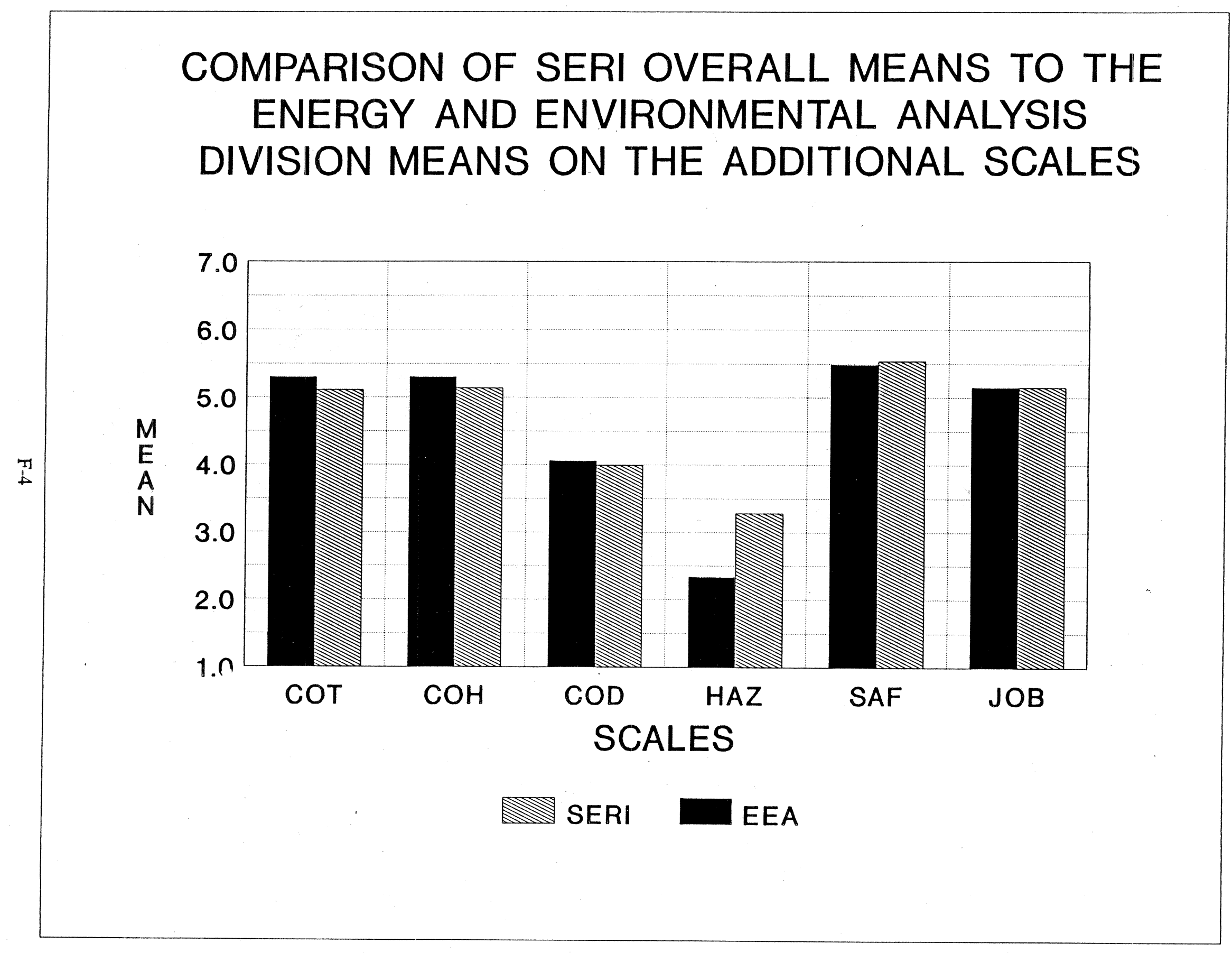




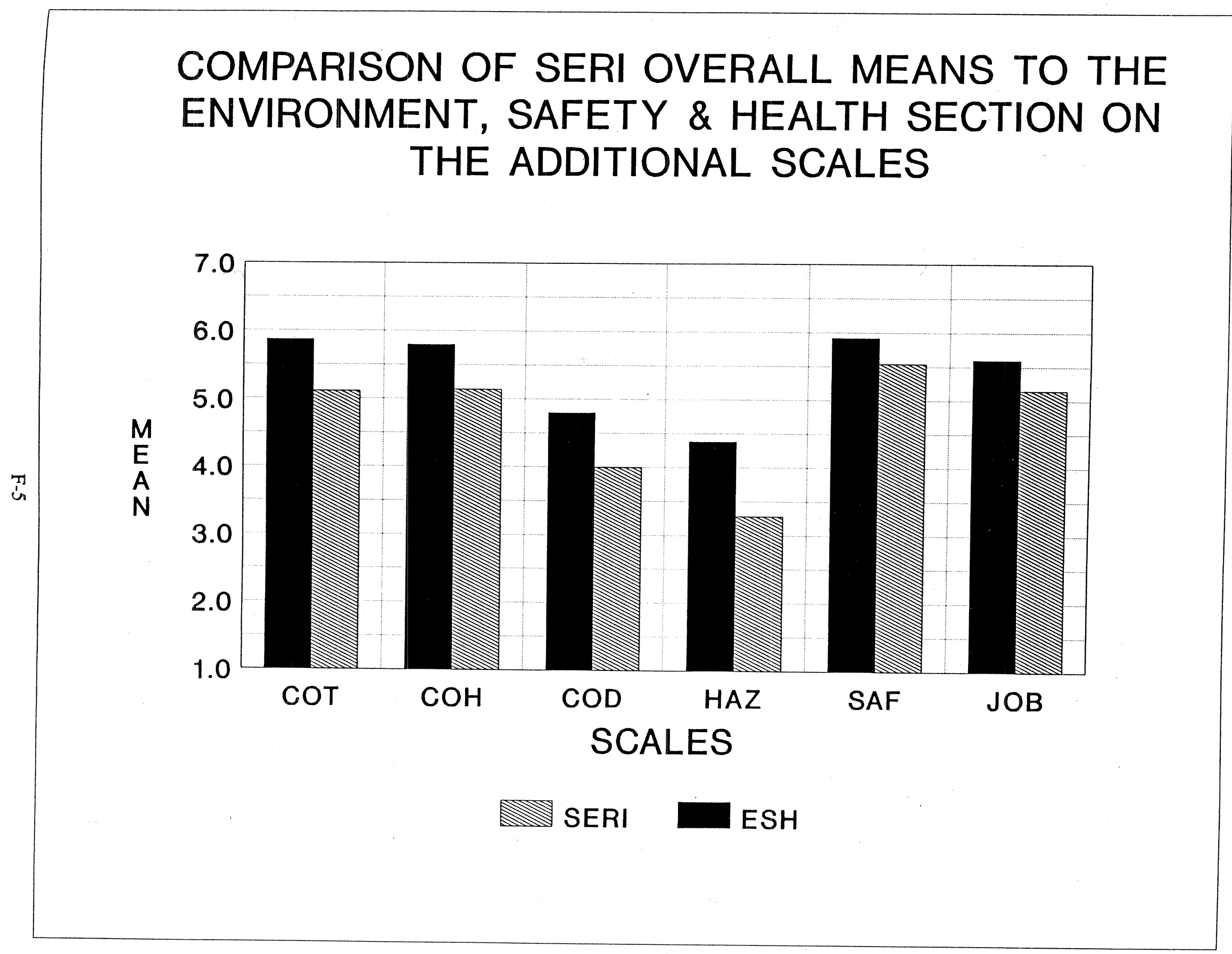




\section{COMPARISON OF SERI OVERALL MEANS TO THE}

FUELS \& CHEMICALS RESEARCH \& ENGINEERING DIVISION MEANS ON THE ADDITIONAL SCALES

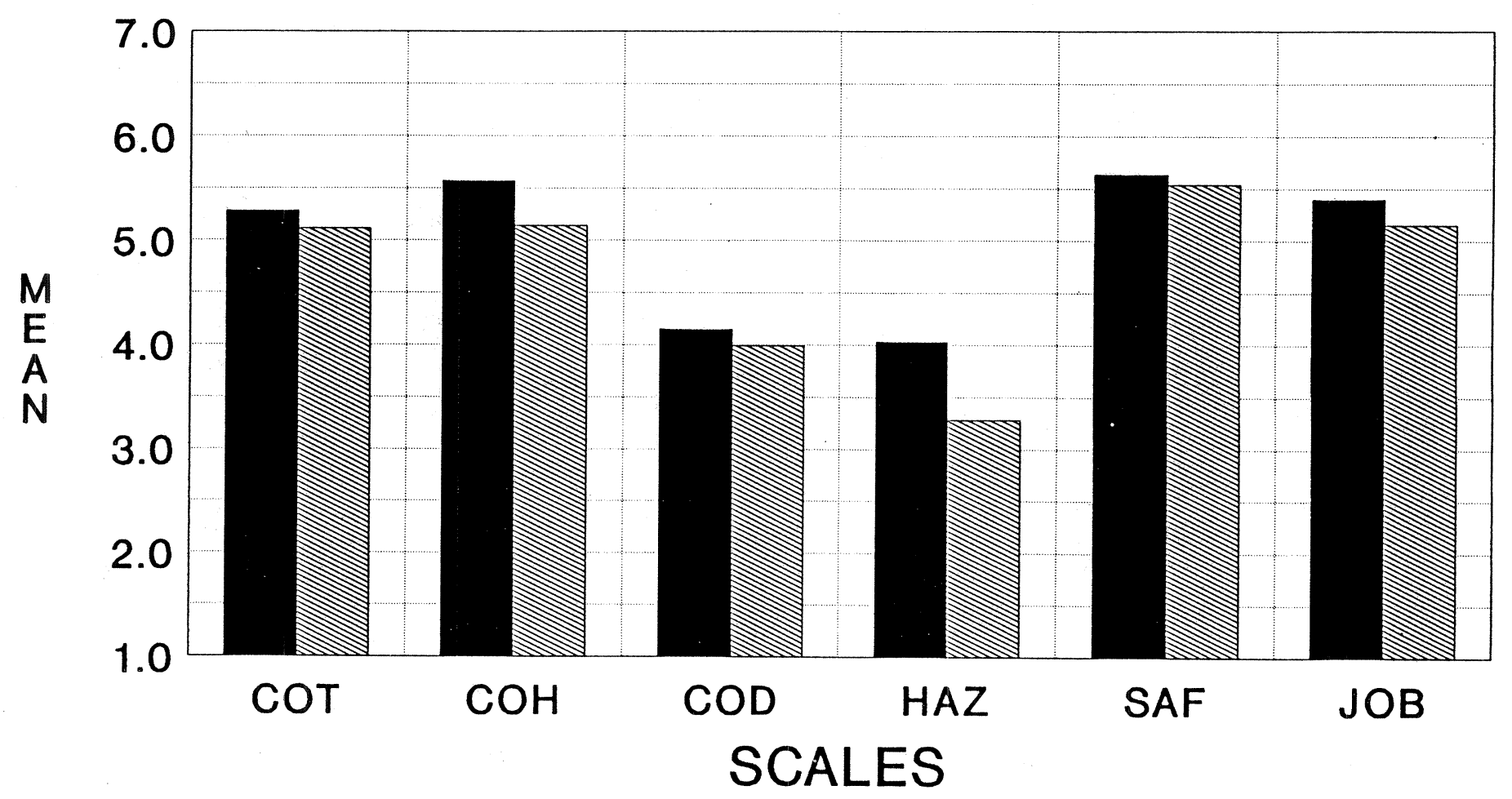




\section{COMPARISON OF SERI OVERALL MEANS TO THE MATERIALS SCIENCE \& ENGINEERING DIVISION MEANS ON THE ADDITIONAL SCALES}

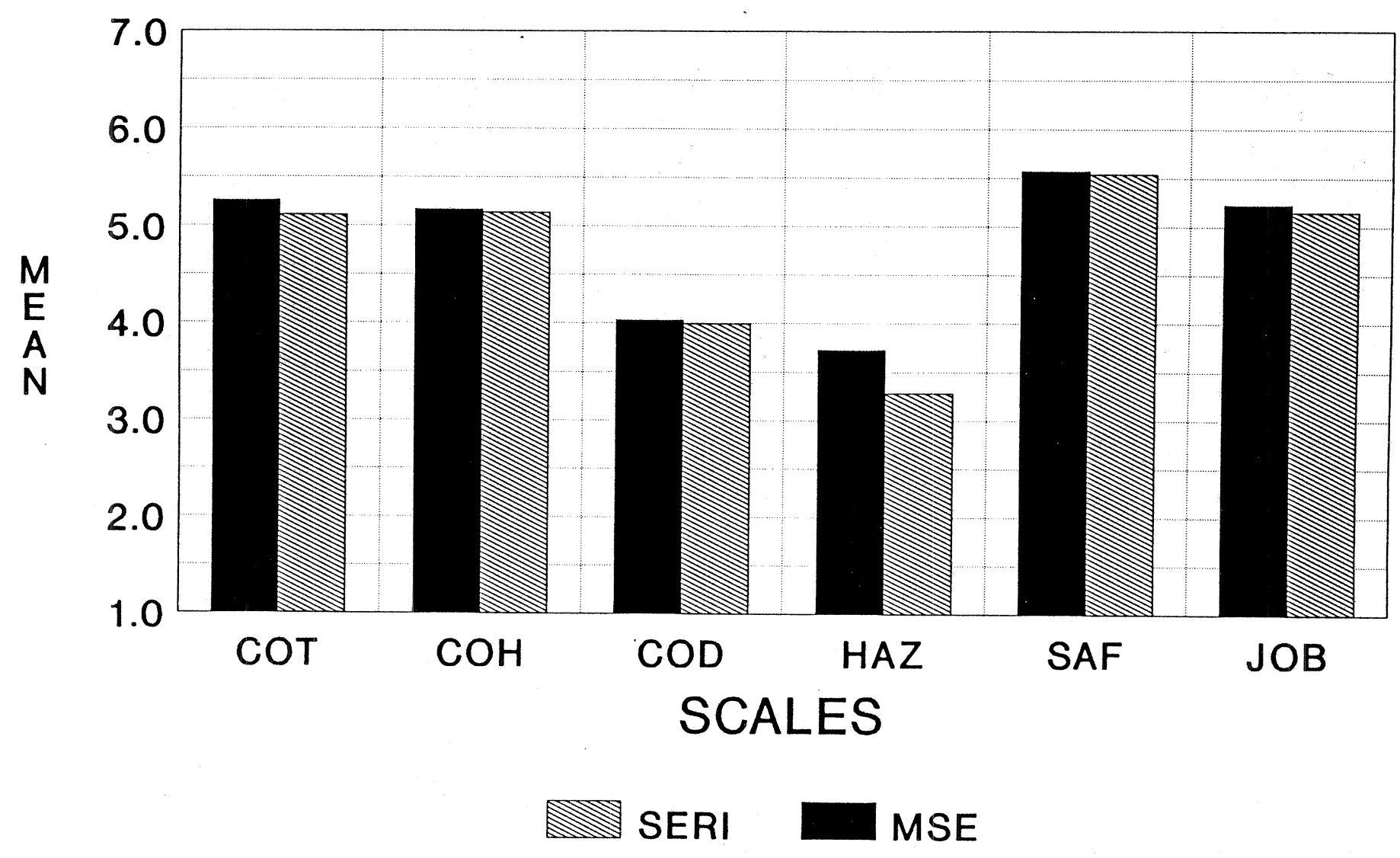




\section{COMPARISON OF SERI OVERALL MEANS TO THE}

MECHANICAL \& INDUSTRIAL TECHNOLOGY DIVISION MEANS ON THE ADDITIONAL SCALES

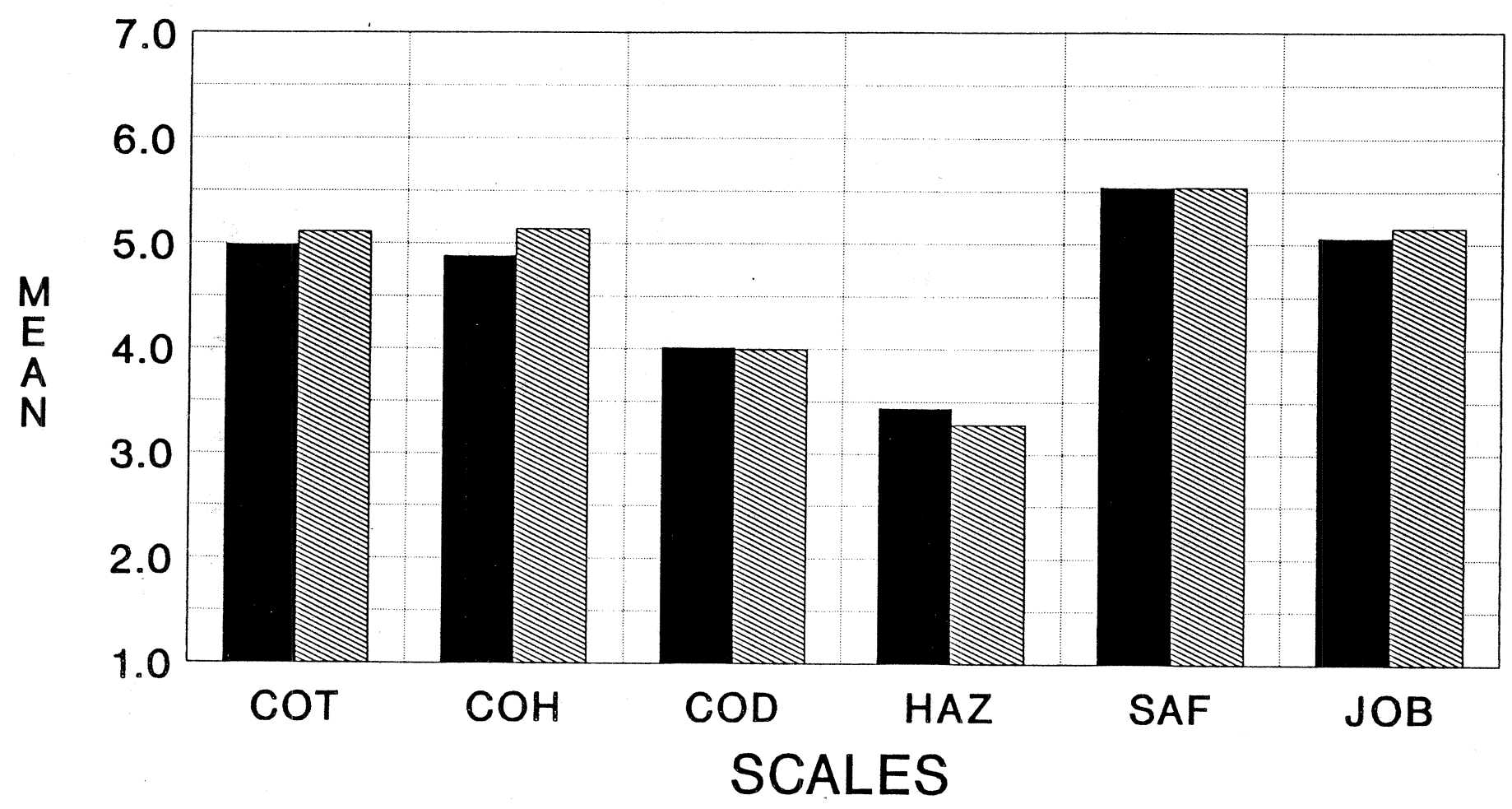




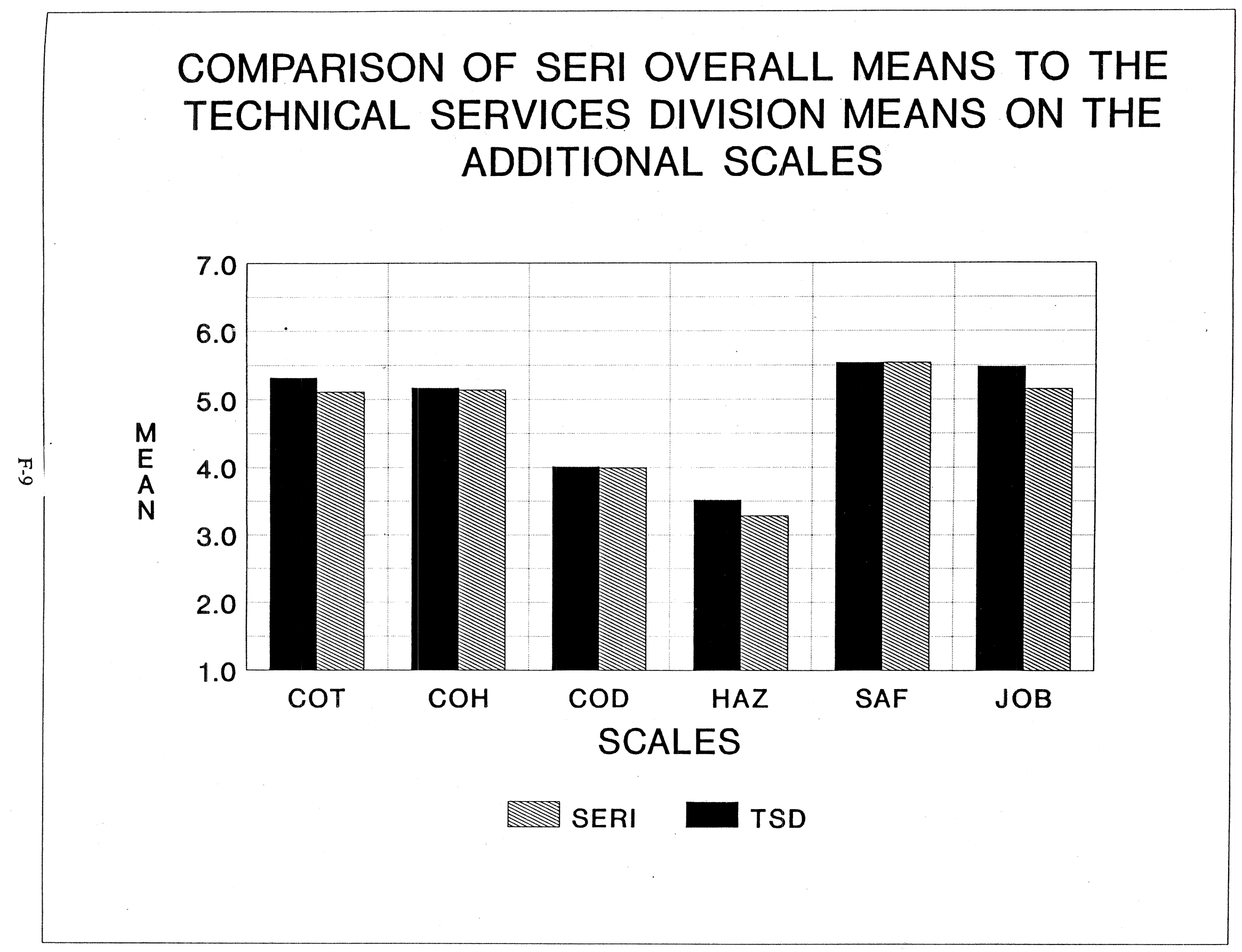


APPENDIX G:

COMPARISON OF SERI DIVISIONS/OFFICES TO OVERALL SERI MEAN VALUES ON ENVIRONMENT, SAFETY AND HEALTH QUESTIONS 


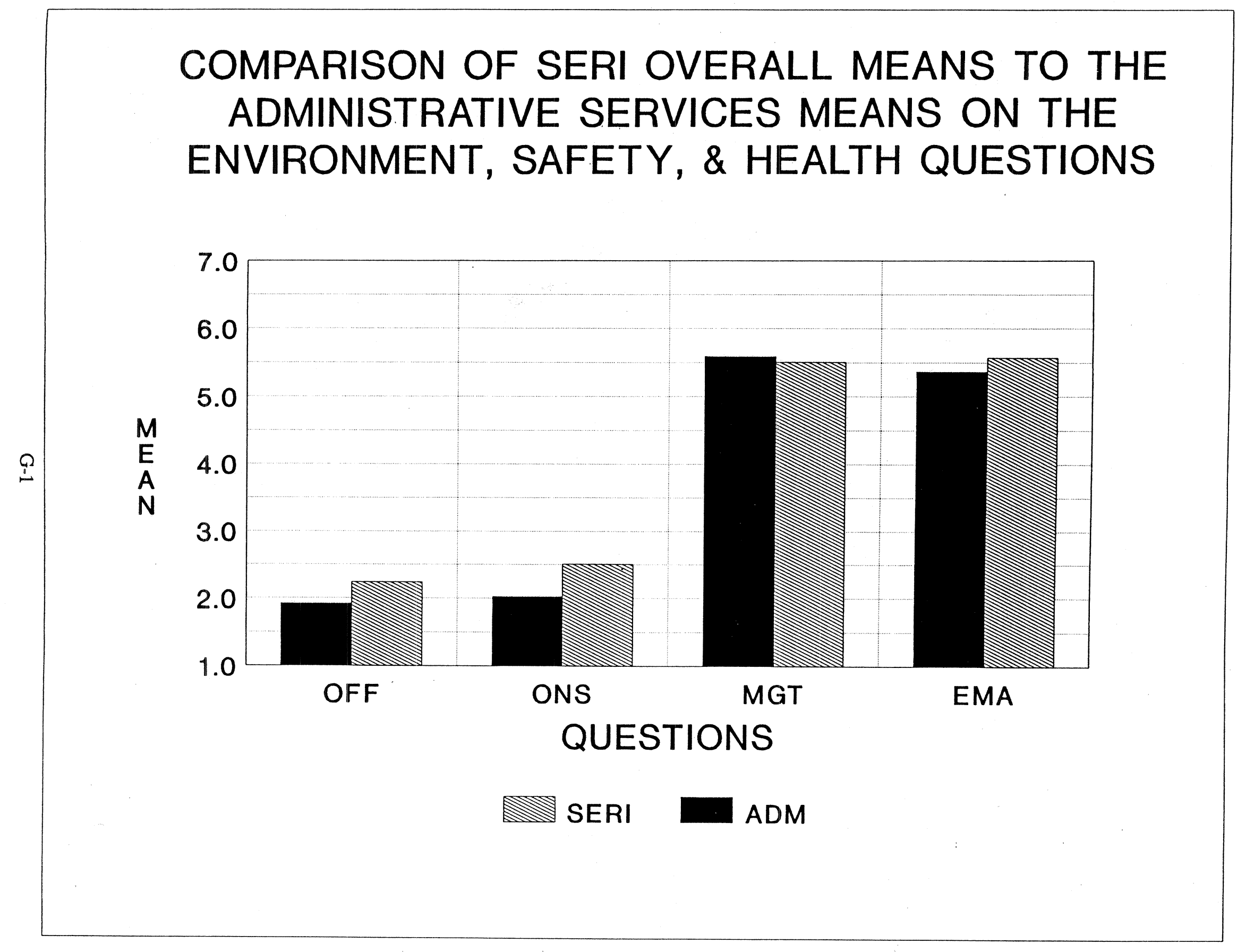


COMPARISON OF SERI OVERALL MEANS TO THE DIRECTOR'S OFFICE MEANS ON THE ENVIRONMENT, SAFETY, \& HEALTH QUESTIONS

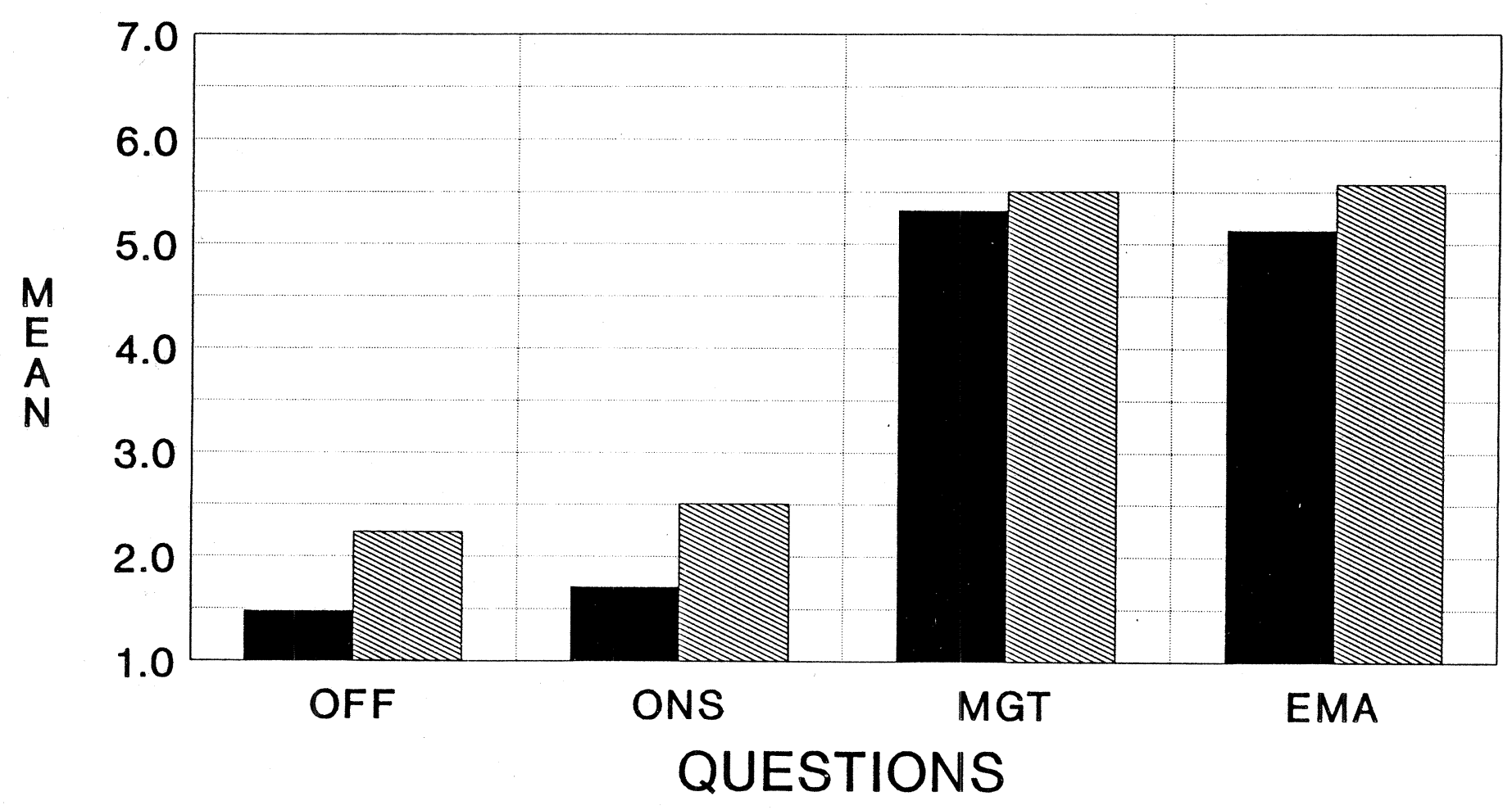

SERI DIR 


\section{COMPARISON OF SERI OVERALL MEANS TO THE}

EEA* DIVISION MEANS ON THE ENVIRONMENT, SAFETY, \& HEALTH QUESTIONS

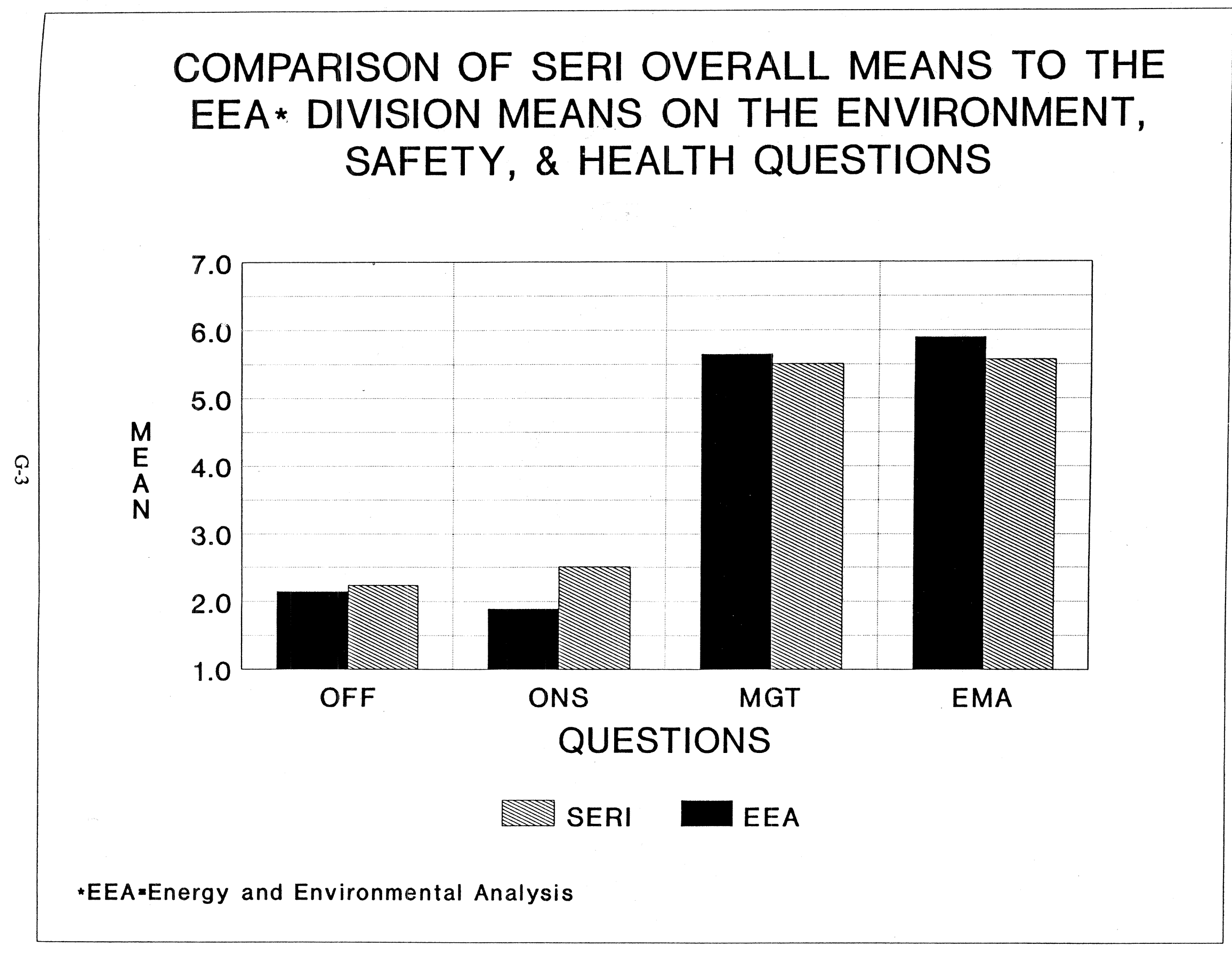


COMPARISON OF SERI OVERALL MEANS TO THE ESH* SECTION MEANS ON THE ENVIRONMENT, SAFETY, \& HEALTH QUESTIONS

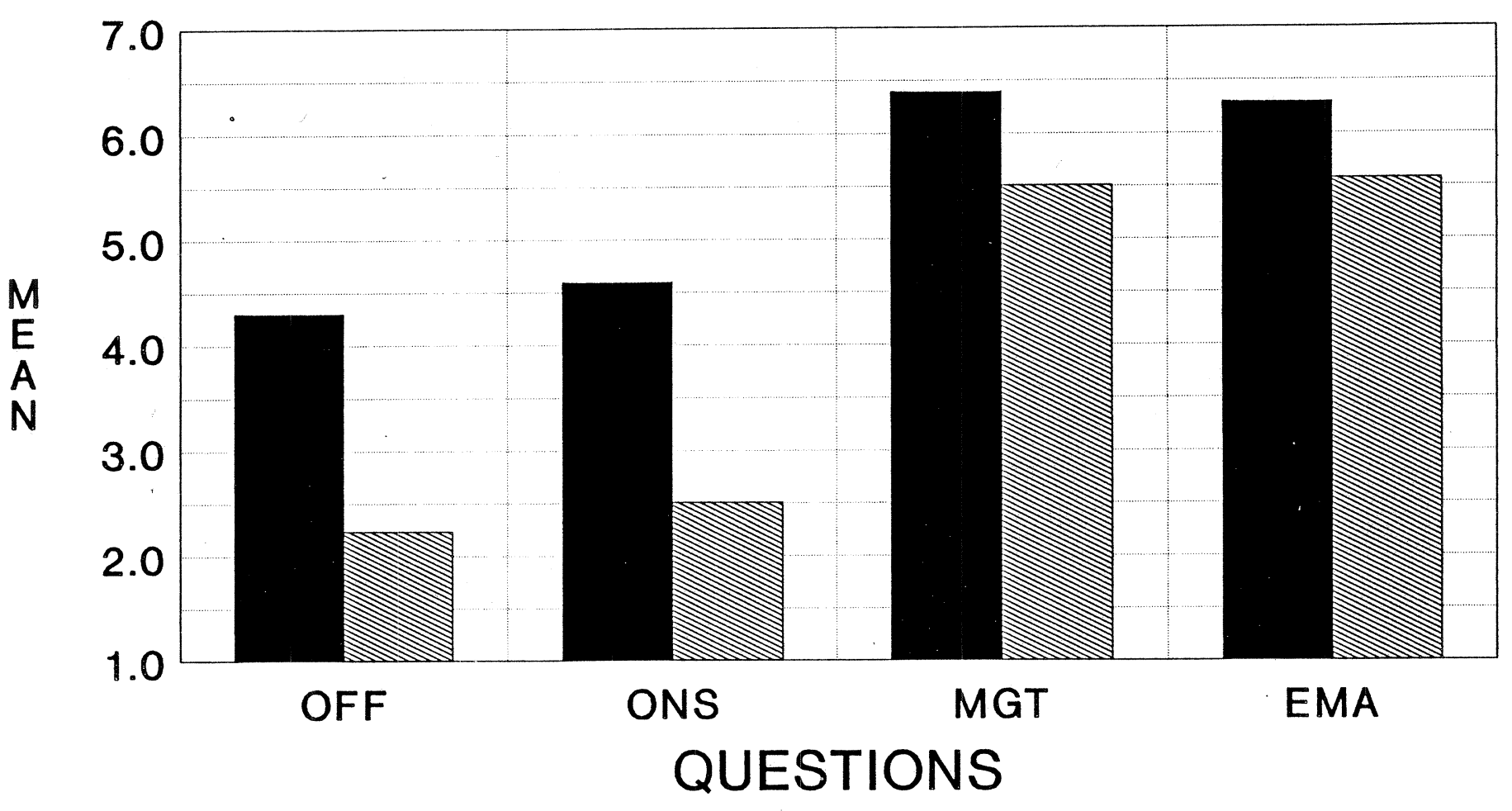

SERI $\square$ ESH 


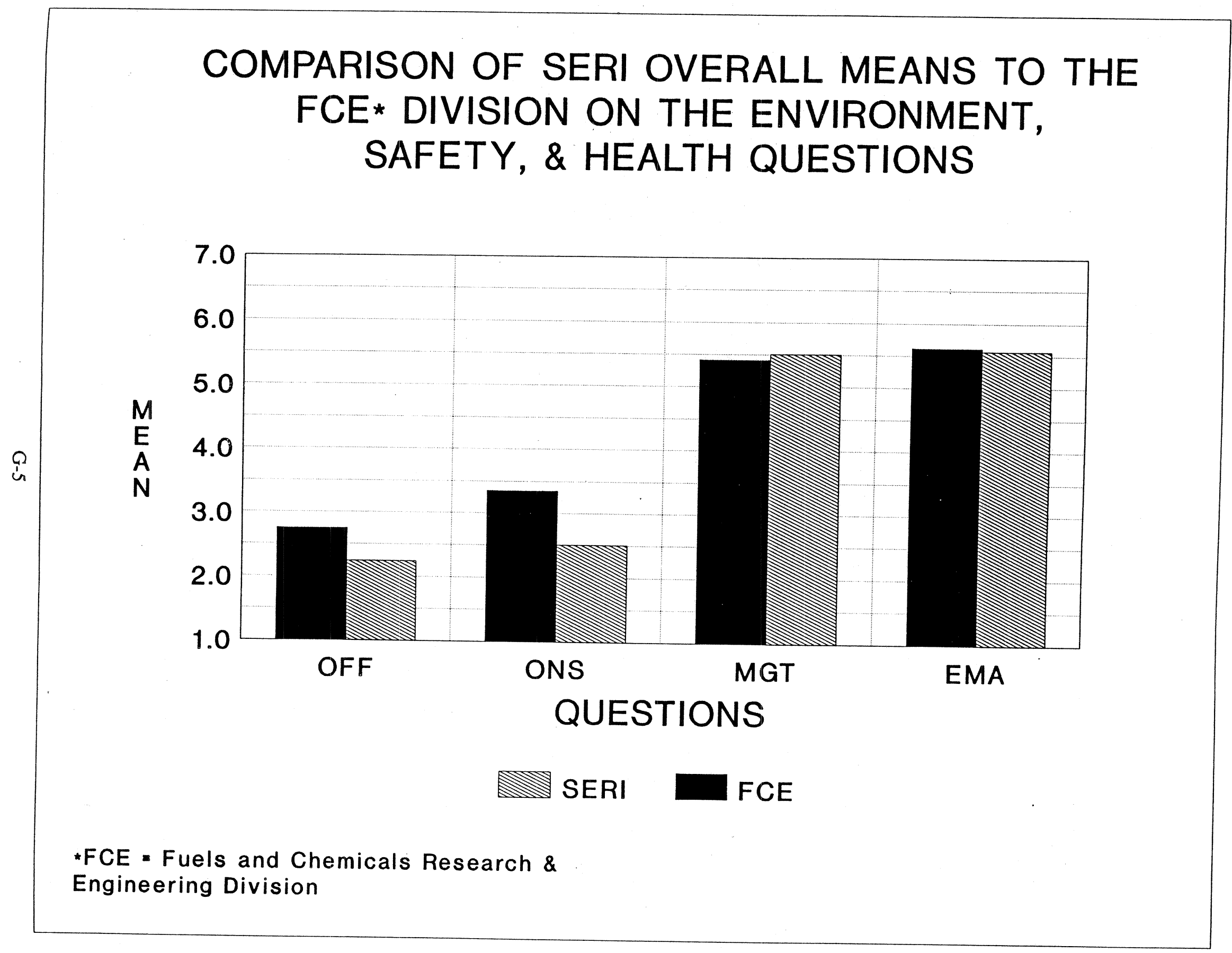




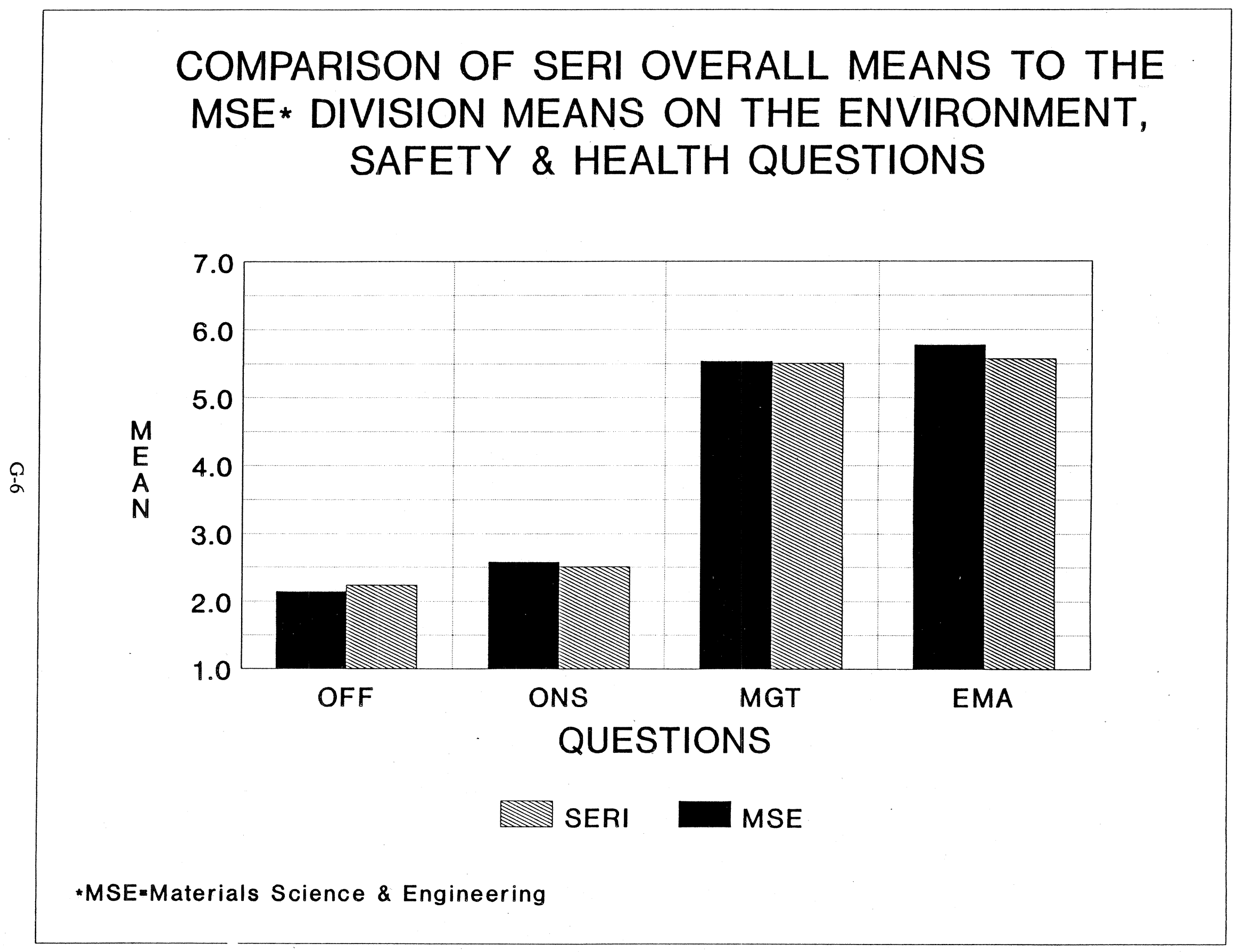




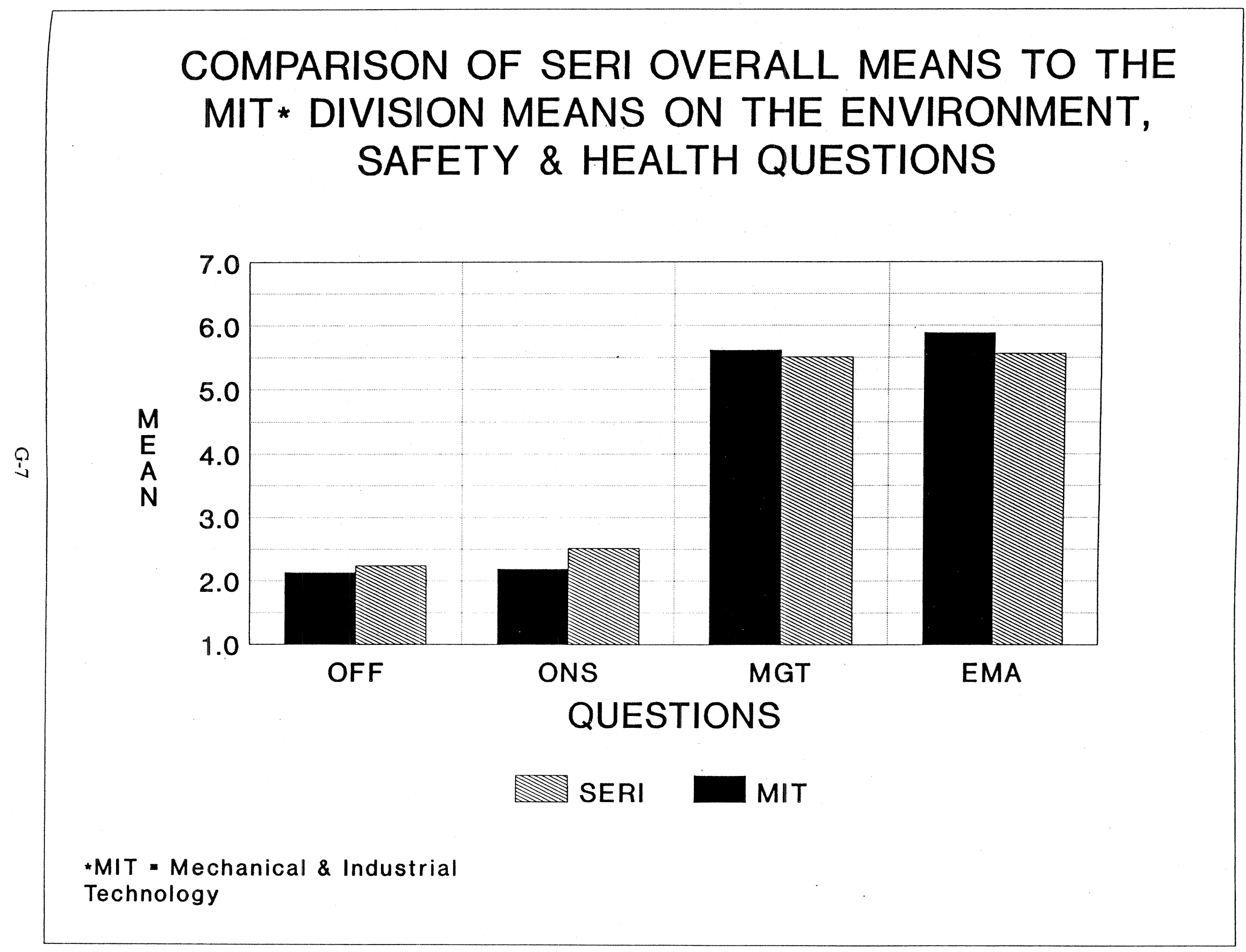




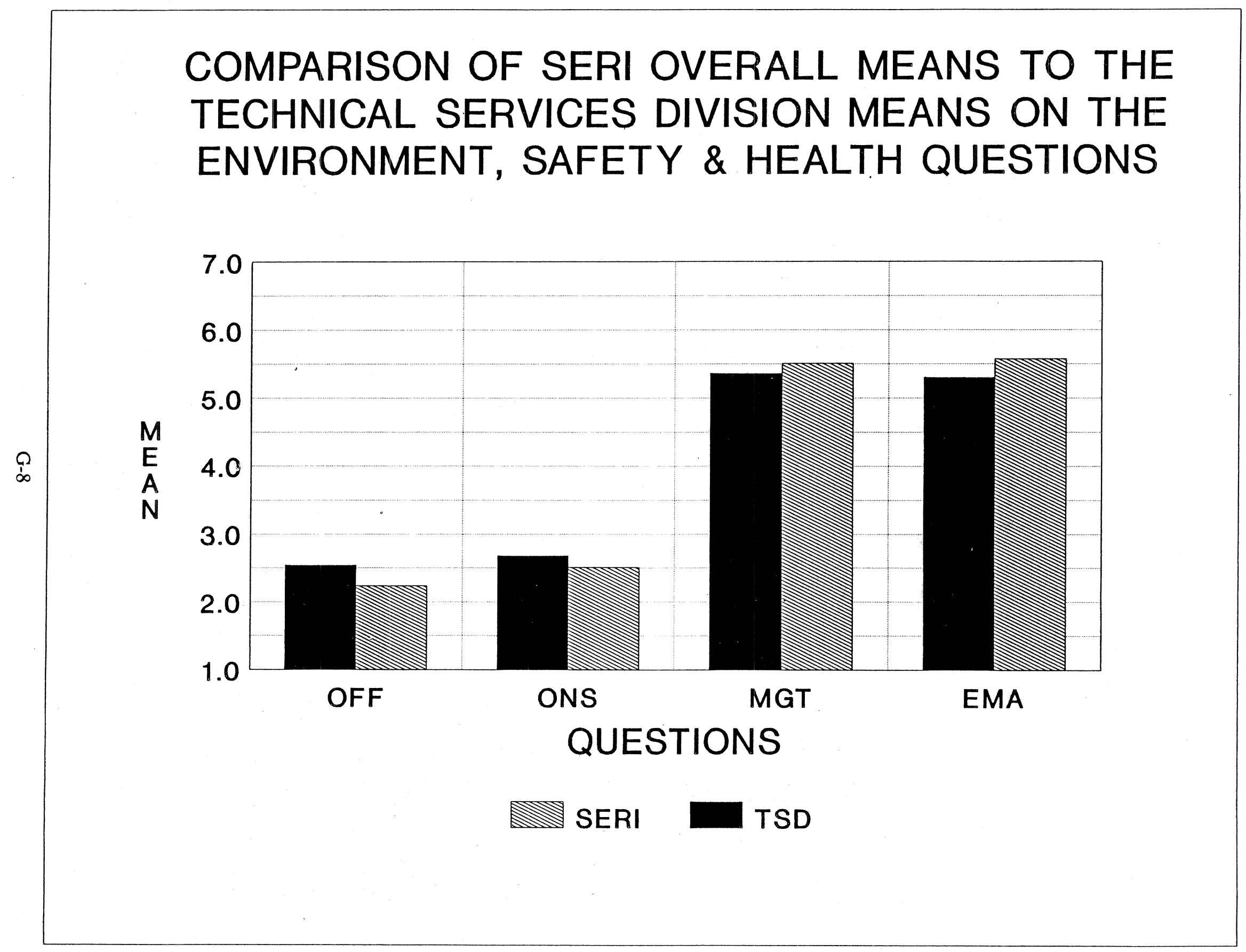

